\title{
ENERGY MANAGEMENT AND COST-BENEFIT ANALYSIS OF SMART GRID
}

\section{REN JIASHENG}

School of Electrical and Electronic Engineering

A thesis submitted to the Nanyang Technological University in fulfillment of the requirement for the degree of Master of Engineering 


\section{Acknowledgements}

This thesis would not have been possible without the guidance and the help of several individuals who in one way or another contributed and extended their valuable assistance in the preparation and completion of this study.

Firstly, I would like to take this opportunity to extend my gratitude and sincere appreciation to Associate Professor So Ping Lam, my supervisor, for his time and guidance given to me during the study of my degree of Master of Engineering. I am sincerely indebted to him for taking great pains to keep me on the right track. His understandings of the research project difficulties faced by me, the willingness to share his knowledge, views, and support have given me a due respect for him.

Next I would like to thank Dr. Tan Kuan Tak and Dr. Sivaneasan Bala Krishnan, for their excellent guidance and providing me with a splendid atmosphere for doing research.

I would also like to extend my appreciation to the technicians of Clean Energy Research Laboratory, Nanyang Technological University for their assistance given to me.

Finally, I would like to thank my wife, Meng Linghui and my child Ren Menghao. They have always been there cheering me up and stood by me through the good time and bad. 


\section{Table of Contents}

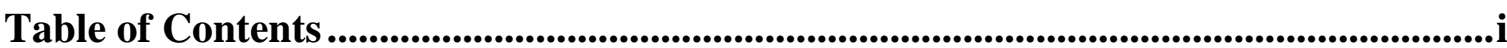

Summary .................................................................................................................................................iii

List of Figures.......................................................................................................................................

List of Tables ........................................................................................................................

List of Notations and Abbreviations ................................................................................................vii

Chapter 1 Introduction .................................................................................................................... 1

1.1 Introduction to Microgrid and Smart Grid ................................................... 1

1.2 Introduction to Energy Management of Smart Grid ....................................... 3

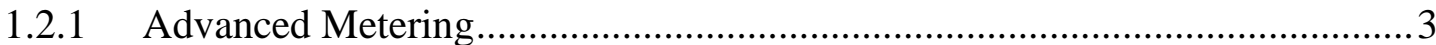

1.2.2 Demand Side Management ........................................................................ 4

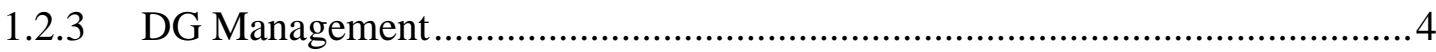

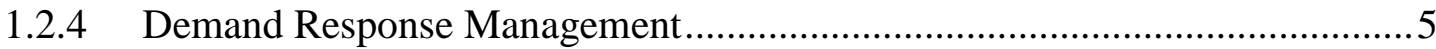

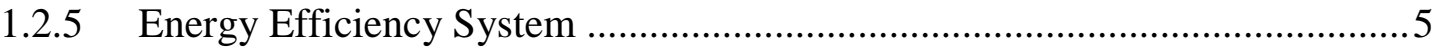

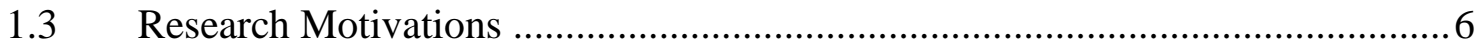

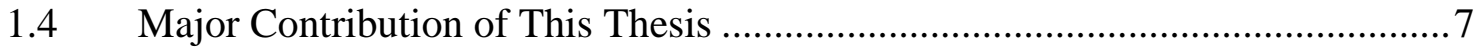

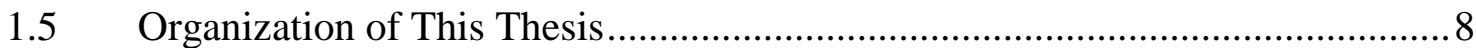

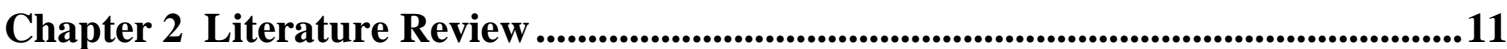

2.1 Centralized and Decentralized Model for EMS ............................................ 11

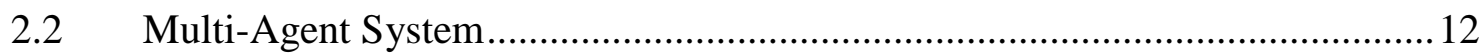

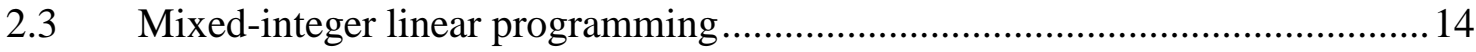

$2.4 \quad$ Energy Management of Smart Grid ........................................................... 15

2.5 Recent Project of Smart Grid Cost-Benefit Analysis ..................................... 15

Chapter 3 Design architecture of Smart Grid's Multi-Agent System .........................17

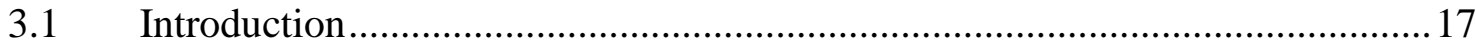

$$
-\mathrm{i}-
$$




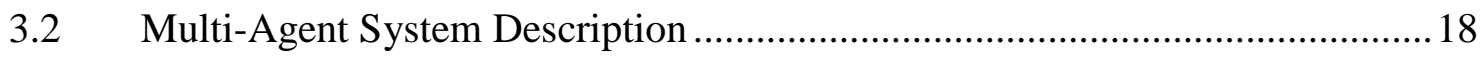

3.3 MILP Problem Formulation of EMS for Smart Grid ....................................25

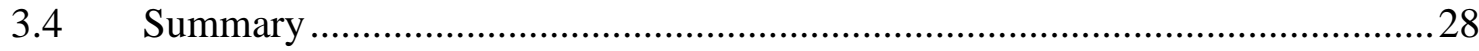

Chapter 4 Sensitivity Analysis of EMS for Smart Grid's Multi-Agent System.........29

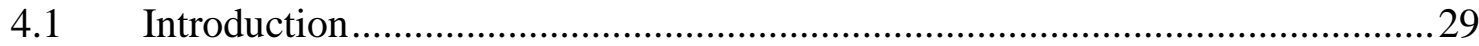

4.2 Test Case 1: Grid-Connected Mode of Operation with Insufficient Energy Generation from PV

4.3 Test Case 2: Islanded Mode of Operation with Insufficient Energy Generation from PV

4.4 Test Case 3: Islanded Mode of Operation with Insufficient Energy Generation from PV and MT 36

4.5 Summary 38

Chapter 5 Business Case Model of the EMS Integration for Smart Grid's Multi-Agent System 39

5.1 Introduction 39

5.2 Cost-Benefit Analysis of Advanced Metering Infrastructure .............................39

5.3 Cost-Benefit Analysis of Demand Response Management ...............................49

5.3.1 Energy Market Authority Model …........................................................50

5.3.2 Cost-Benefit Analysis of Implementing Demand Response in Smart Grids.51

$5.4 \quad$ Cost-Benefit Analysis of Energy storage .....................................................53

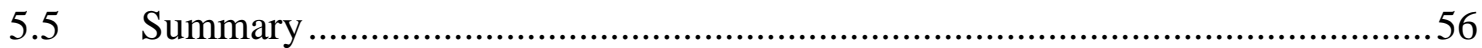

Chapter 6 Conclusions and Recommendations for Future Research ............................57

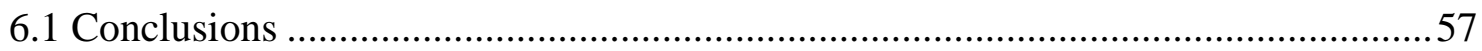

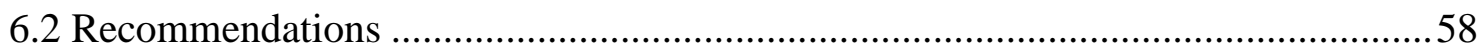

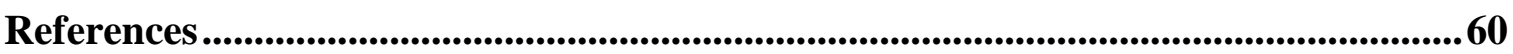

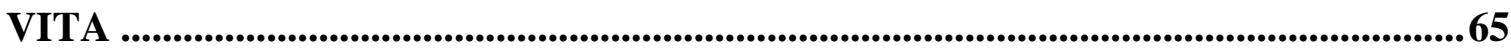




\section{Summary}

A single microgrid can only generate and distribute power within a localized area. Furthermore, in the event of unavailability/failure of one or more distributed energy resources (DERs) in the single microgrid during islanded mode of operation, the single microgrid itself may not be secure enough to meet its own load demand due to restricted energy generation capability. The additional power is required from utility grid or other microgrids in which they are in adjacent locations and interconnected to supply power to each other. Thus, an Energy Management System (EMS) is required to monitor, control, and optimize the generation, distribution and transmission of energy. This thesis presents a hierarchical architecture design for multi-microgrid using the Multi-Agent System concept to be incorporated into the Energy Management System. The optimum solution for the energy management is Mixed-Integer Linear Programming (MILP) to determine the minimum energy trading costs in the multi-microgrid system and the power balance within the multi-microgrid system is achieved through energy trading between different microgrids in a smart grid system.

In general, current smart grid control systems adopt either the centralized or decentralized control strategy. The proposed novel hierarchical multi-microgrid control system using the Multi-Agent System (MAS) concept has the capability to handle multi-objective and multiconstraint complex systems. Furthermore, the novel energy trading scheme by using the Mixed-Integer Linear Programming (MILP) is able to improve the economical and effectiveness of the control systems for all the agents in a multi-microgrid system. The proposed hierarchical multi-microgrid system based MAS is a pioneering research in the smart grid domain. The interconnection of multiple microgrid systems in adjacent locations to assist during supply constraint in a single islanded microgrid system will ensure enhanced reliability and security of supply. This novel approach is expected to replace the undesired load shedding technique employed in current smart grid systems. In addition, the 
energy management system is developed to achieve optimum energy trading between different microgrids in a smart grid system.

Currently, most research workers on smart grid focus on the development and application of the smart grid concept. However, there have been very few research work (none in the Singapore context) addressing the realistic conditions for implementing the smart grid concept. The novel business models, which include cost-benefit analysis of infrastructure of smart grid, especially in the areas of investment costs, cost savings and payback years for integration of smart grid in Singapore, is proposed in this thesis. 


\section{List of Figures}

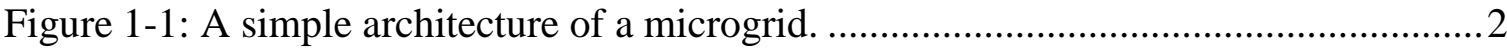

Figure 1-2: A simple control/communication diagram of energy management system......3

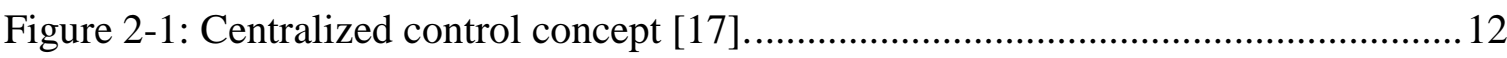

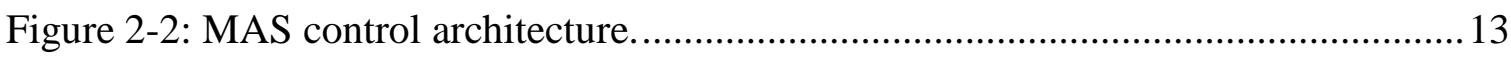

Figure 3-1: Proposed three-level hierarchical smart grid architecture design. ................... 18

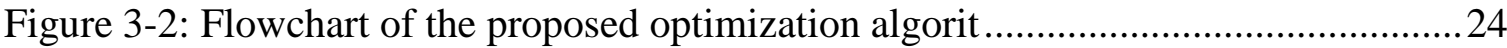

Figure 4-1: Test Case 1: Power supplied to microgrids with load demand.......................32

Figure 4-2: Test Case 2: Power supplied to microgrids with load demand.......................35

Figure 4-3: Test Case 3: Power supplied to microgrids with load demand.......................38

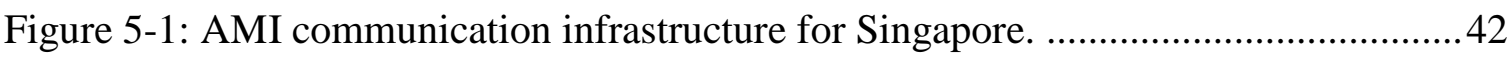

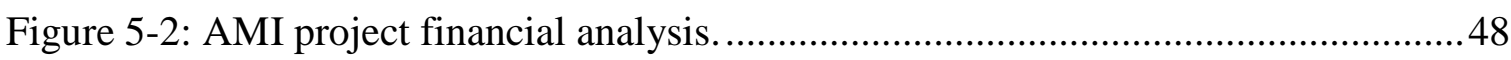




\section{List of Tables}

Table 4.1 Transmission cable power limits and resistances ...........................................30

Table 4.2 DER and demand response parameters from level 2 microgrid agents .............30

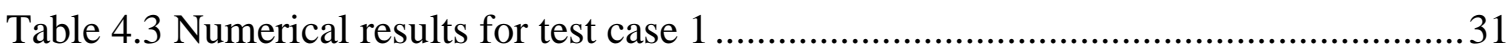

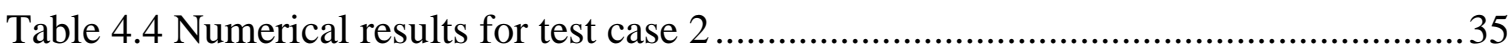

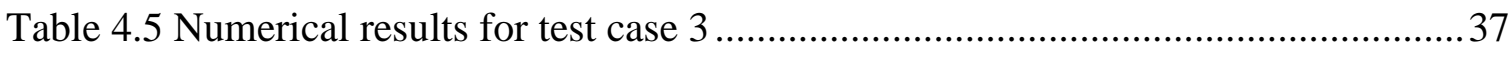

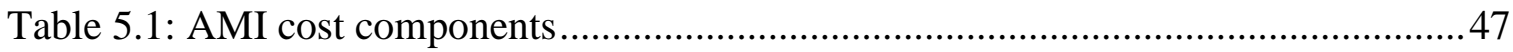

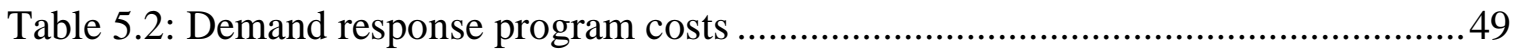

Table 5.3: Demand response program benefits ..............................................................50

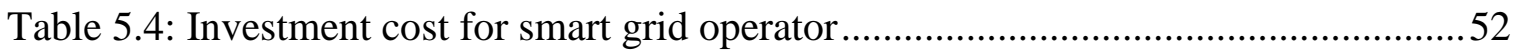

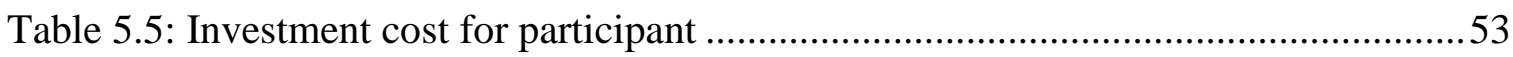

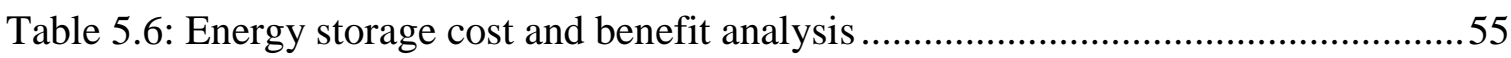




\section{List of Notations and Abbreviations}

\section{List of notations}

$\lambda^{P V}: \quad \quad$ cost of PV energy generation

$Y: \quad$ expected payback year

$I_{y}: \quad$ investment expenditure in the $y^{\text {th }}$ year

$M_{y}$ : $\quad$ operation and maintenance cost in the $y^{\text {th }}$ year

$r: \quad$ annual effective discount rate

$E_{y}: \quad$ total energy production of the PV system in the $y^{\text {th }}$ year

$\lambda^{M T}: \quad$ fuel cost of MT energy generation

$P_{M T}: \quad \quad$ output power of the MT

$a, b, c: \quad$ constant coefficients in $\$ / \mathrm{hr}, \$ / \mathrm{MWhr}$ and $\$ / \mathrm{MW}^{2} \mathrm{hr}$

$\lambda^{D R}: \quad \quad$ cost of demand response

$m: \quad$ number of loads to be shed

$C_{i}: \quad \quad \quad$ value of the load $i$ without demand response

$\Delta T: \quad$ time interval in hours

$P_{i}: \quad$ power demand of load $i$

$C_{\text {TET }}$ minimum total energy trading cost

$C_{P V,:} \quad$ total energy cost of PV

$C_{M T:} \quad$ total energy cost of MT

$C_{D R}: \quad$ total energy cost of DR

$C_{\text {Grid: }} \quad$ total energy cost of electricity grid

$k: \quad \quad$ each half-hour interval in a day which takes the values of $1,2,3 \ldots, 48$

$P_{i, j}^{P V}(k): \quad$ total amount of power transferred from PV from microgrid $i$ to microgrid $j$ at time interval $k$

$P_{i, j}^{M T}(k): \quad$ total amount of power transferred from MT from microgrid $i$ to microgrid $j$ at time interval $k$

$$
- \text { vii }-
$$


$P_{i, j}^{D R}(k): \quad$ total amount of power transferred from DR from microgrid $i$ to microgrid $j$ at time interval $k$

$P_{j}^{\text {Grid }}(k)$ : $\quad$ amount of power purchased by microgrid $j$ from the electricity grid at time interval $k$

$\lambda^{\text {Grid }}(k)$ : $\quad$ energy price of the electricity grid at time interval $k$

$D_{j}(k): \quad$ total amount of load demand of microgrid $j$ at time interval $k$

$P_{i}^{P V, \max }(k): \quad$ maximum available power of $\mathrm{PV}$ of $i^{\text {th }}$ microgrid at time interval $k$

$P_{i}^{M T, \max }(k): \quad$ maximum available power of MT of $i^{\text {th }}$ microgrid at time interval $k$

$P_{i}^{D R, \max }(k): \quad$ maximum available power of DR of $i^{\text {th }}$ microgrid at time interval $k$

$P_{i}^{M T, \min }(k): \quad$ minimum operation power of the MT at time interval $k$

$x: \quad$ a binary variable which takes the value of 1 if the MT is supplying power at time interval $k$, else 0

$P_{i, j}^{\max }: \quad \quad \quad$ maximum power that can be transferred from microgrid $i$ to microgrid $j$ due to transmission cable power limit

$P_{i, j}^{L}(k): \quad$ transmission cable power loss incurred due to power transfer from microgrid $i$ to microgrid $j$ at time interval $k$

$V_{i, j}: \quad \quad \quad \quad \quad$ transmission line voltage between microgrid $i$ and microgrid $j$

$\cos \varphi: \quad$ power factor

$R_{i, j}^{C}: \quad$ transmission cable resistance of microgrid $i$ and microgrid $j$

$\lambda_{m m}: \quad$ market clearing price

$P_{t}^{E}: \quad \quad$ output power of ESS during period $t$

$\lambda$ : $\quad$ annual growth rate of smart meter

$D V: \quad$ depreciation value

$D_{Y}: \quad$ number of deployment years of the AMI project 
$\lambda_{1 \Phi,} \lambda_{3 \Phi}: \quad$ annual growth rate in percentage of single-phase meters and three-phase meters

$N_{i, 1 \Phi,} N_{i, 3 \Phi:} \quad$ initial number of single-phase meters and three-phase meters that will be deployed at the start of the AMI project

$C_{i, 1 \Phi,} C_{i, 3 \Phi:} \quad$ cost in dollars of one new single-phase and one new three-phase meters

$I_{i, 1 \Phi,} I_{i, 3 \Phi}: \quad$ installation cost in dollars of one single-phase and one three-phase meters

$N_{e, 1 \Phi,} N_{e, 3 \Phi:} \quad$ existing number of single-phase and three-phase meters that would be replaced by a smart meter

$C_{e, 1 \Phi,} C_{e, 3 \Phi:} \quad$ cost in dollars of one existing single-phase and one existing three-phase meters

$S V_{e, 1 \Phi,} S V_{e, 3 \Phi}:$ salvage value in dollars of one existing single-phase and one existing threephase meters

$B Y_{e, 1 \Phi,} B Y_{e, 3 \Phi:}$ balance number of useable years of one existing single-phase and one existing three-phase meters

$C_{P I P}: \quad$ communication network preparation cost

$C_{C N P}: \quad$ forecast irradiance of the $i$ th $\mathrm{PV}$ unit during period $t$

$L_{O, 1 \Phi}, L_{O, 3 \Phi}: \quad$ outage losses in dollars of one existing single-phase and one existing threephase meters

$N_{D C U}: \quad$ number of data concentrator units required for the AMI project

$N_{W A N}: \quad$ number of WAN hardware equipment required for the AMI project

$N_{B E}: \quad$ number of backend communication equipment required for the AMI project

$C_{D C U}: \quad$ cost in dollars of one data concentrator unit

$C_{W A N}: \quad$ cost in dollars of one WAN hardware equipment

$C_{B E}: \quad$ cost in dollars of one backend communication equipment

$I_{D C U}: \quad$ installation cost in dollars of one data concentrator unit

$I_{W A N}: \quad$ installation cost in dollars of one WAN hardware equipment

$I_{B E}: \quad$ installation cost in dollars of one backend communication equipment

$C_{I T}: \quad$ total cost for the IT system and integration

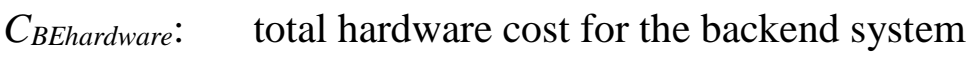

$C_{M D M S}: \quad$ cost of the MDMS software 
$C_{P M}: \quad \quad$ project management cost

$P M_{\text {cost }}: \quad$ annual cost for project management

Cом: $\quad$ annual metering O\&M cost

$C_{M O}: \quad$ annual metering operation cost

$C_{C O}: \quad$ annual communication operation cost

$S L_{\text {fees }}: \quad$ total annual software cost

$C L_{\text {fees: }} \quad$ annual communication network licensing fees

$M_{I T}: \quad$ annual IT system operating manpower cost

$P_{Y:} \quad$ project life cycle in years

$C_{A M I}: \quad$ total AMI cost over the project life cycle

$S_{M R}: \quad$ annual saving in meter reading cost

$N_{M R}: \quad$ number of meter readers

$A S_{M R}: \quad$ average annual salary of meter readers

$T_{M R}: \quad$ annual transportation cost for manual meter reading

$C_{A M R}: \quad$ annual AMR meter reading cost

$S_{U E}: \quad$ annual cost saving in reduction of unaccounted for energy

$T_{U E}: \quad$ annual theft/tamper-associated revenue loss

$F_{U E}: \quad$ annual revenue loss for unaccounted energy due to failed meter

$S_{F M S}: \quad$ annual cost saving in reduction of field and meter services

$M_{M C}: \quad$ annual cost for manual disconnect/reconnect of meters

$M_{S R}: \quad$ annual cost for manual off-cycle/special meter reads

MOR: $\quad$ annual cost for redundant outage field trips

$T_{F M S}: \quad$ annual transportation cost for carrying out field and meter services

$S_{A M I}: \quad$ annual AMI cost saving

$U S E P_{w / o}: \quad$ counterfactual USEP generated without the load curtailed

$U S E P_{w}: \quad$ actual USEP with the load curtailed

$E_{c}$ : $\quad$ total energy committed by the participant for DR per year

Com: incremental overheads and maintenance costs

$C_{i}: \quad$ incremental initial cost

$E_{i}: \quad$ total energy demand 

$E_{r c}: \quad$ energy demand associated with regulatory contracts
$h r: \quad$ number of operating hours
$T: \quad$ payback period
I: $\quad$ initial investment
$R: \quad$ revenue per annum
$S O C_{\text {min }}$ : minimum state of charge
$C_{d d c}: \quad$ energy storage capacity in $\mathrm{kWh}$
$C_{E S}$ : $\quad$ incremental overheads and maintenance costs
$P_{\text {sell }}: \quad$ electricity tariff charged to consumer in $\$ / \mathrm{kWh}$
$P_{\text {off-Peak }}: \quad$ grid off-peak period electricity tariff in $\$ / \mathrm{kWh}$

\section{$\checkmark$ List of abbreviations}

DG distributed generation

DER distributed energy resources

PV photovoltaic

MT microturbine

EMS energy management system

AMI advanced metering infrastructure

DSM demand side management

DR demand response

MAS multi-agent system

MILP Mixed-integer linear programming

NTU Nanyang Technological University

UC unit commitment

ED economic dispatch

AMS agent management system

DF directory facilitator 
ILP integer linear programming

IES intelligent energy system

LNG liquefied natural gas

SoC state-of-charge

LCOE levelized cost of energy

MG microgrid

O\&M operation and maintenance

AMR automated meter reading

WAN wide area network

IT Information Technology

MDMS meter data management system

MCE market clearing engine

USEP uniform singapore energy price

IDRP implicit demand response rebate 


\section{Chapter 1}

\section{Introduction}

\subsection{Introduction to Microgrid and Smart Grid}

A microgrid is an electrical system that includes multiple loads and distributed energy sources that can be operated in parallel with the broader utility grid or a small, independent power system. It increases reliability with distributed generation(DG), increases efficiency with reduced transmission line length, and allows easier integration of alternative energy sources. It consists of a low-voltage distribution network with distributed energy resources (DERs) such as solar photovoltaics (PVs), wind turbines, microturbines (MTs) and fuel cells together with power converters, energy storage devices, and customer loads, operated in either grid-connected or islanded mode of operation. Microgrid concept is advantageous to network operation due to its sophisticated control capability. Under normal condition, the microgrid operates in grid-connected mode but switches to islanded mode in case of faults in upstream network.

Compared to conventional distribution network architectures, the microgrid provides improved service quality and reliability, reduced carbon emissions, and probably lower cost of electricity to end users. The microgrid design concepts and control strategies to efficiently integrate DERs into the single microgrid have been extensively researched and developed [1], [2]. A simple architecture of a microgrid is shown in Figure 1-1 [3]. The microgrid also can be considered as subsystem of smart grid. 


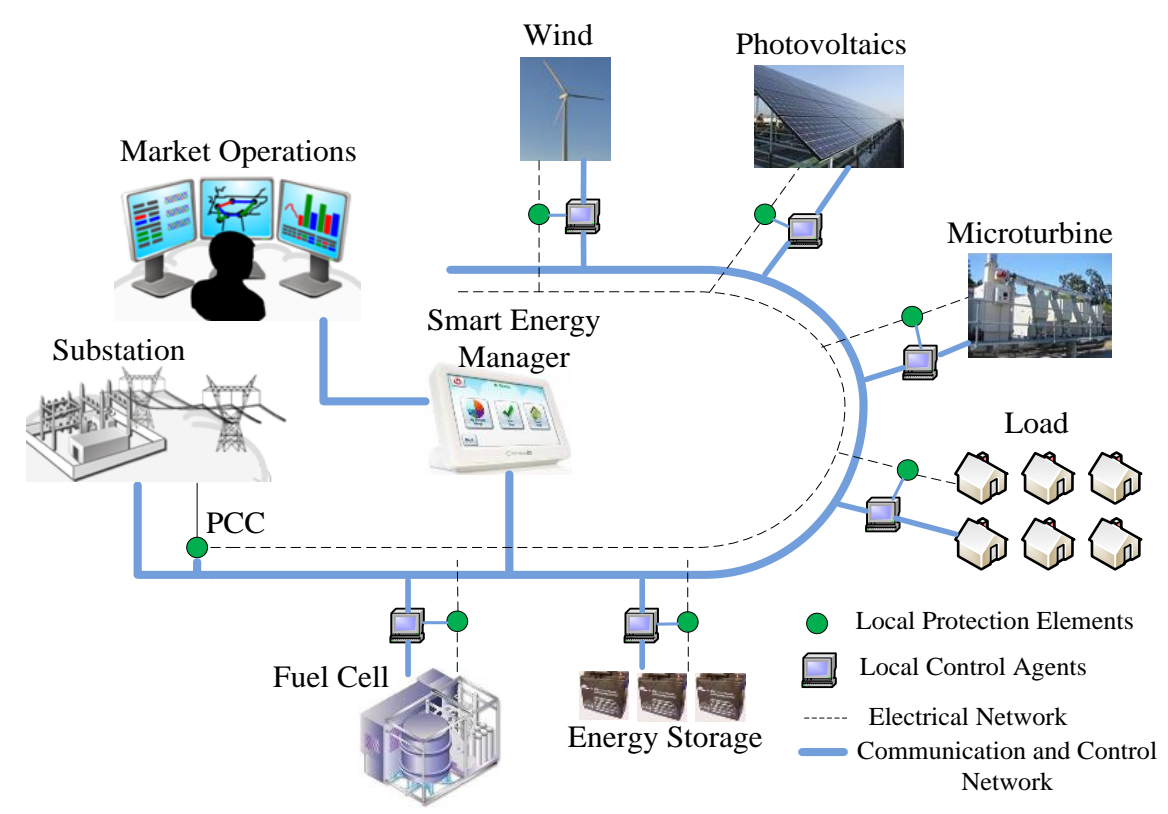

Figure 1-1: A simple architecture of a microgrid.

A smart grid is a modernized electrical grid that uses information and communications technology to gather and act on information, such as information about the behaviors of suppliers and consumers, in an automated fashion to improve the efficiency, reliability, economics, and sustainability of the production and distribution of electricity [4]. In comparison to microgrids, smart grids have wide area monitoring, control and protection, digital information and dynamic optimization of grid operation and resources, demand responses, demand-side resources, distributed resources, energy management, smart metering system. Furthermore, two-way communication is possible between consumers and utility services in the smart grid system. The smart grid will allow utilities to distribute electricity around the system as efficiently and economically as possible. It will also allow and encourage the consumers to use electricity as economically as possible while reducing consumption.

The smart grid is already build in many of the countries such as Canada, US, China and India. In 2009, the Singapore government announced a $\$ 1$ billion sustainable-development blueprint to build a greener, more energy efficient and sustainable nation [5]. Part of the plan is to promote the integration of smart grid on rooftops of high-rise Housing 
Development Board (HDB) residential buildings [6]. In the last few years, there has been a prolific growth in the integration of smart grid to the distribution network in Singapore [7]- [9]. In 2010, solar PV systems of smart grid valuing up to $\$ 2.3$ million were installed on the roofs of HDB buildings to generate electricity for the public areas of each building [9].

\subsection{Introduction to Energy Management of Smart Grid}

An energy management system (EMS) is a system of computer-aided tools used by operators of electric utility grids to monitor, control, and optimize the performance of the generation and/or transmission system. It behaves as a central controller of the smart grid, responsible for sending and receiving monitoring and control information to and from intelligent energy sensors and smart meters. A simple control/communication diagram of energy management system is in Figure 1-2.

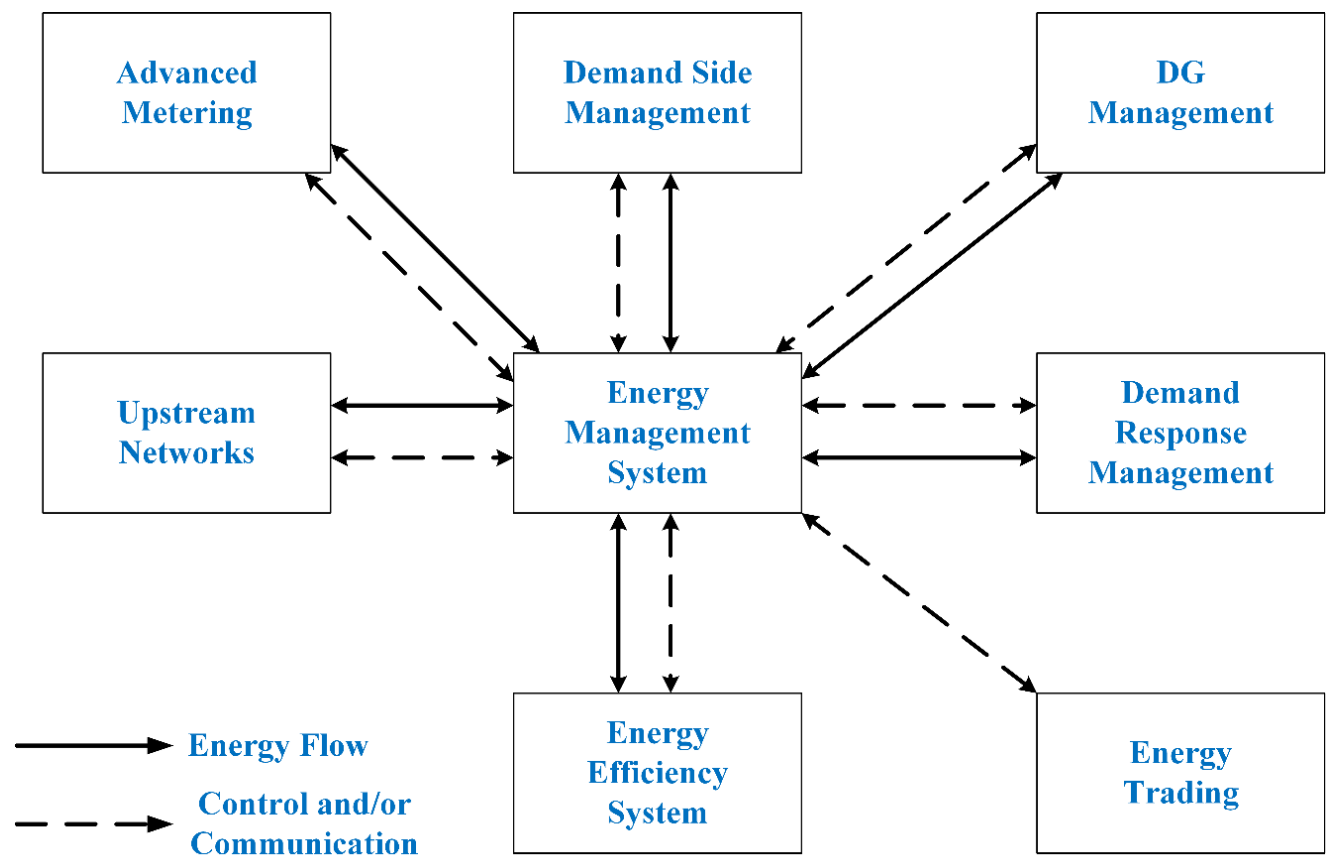

Figure 1-2: A simple control/communication diagram of energy management system.

\subsubsection{Advanced Metering}


The advanced metering infrastructure (AMI) will facilitate versatile and flexible reading and control capabilities to form the backbone of an efficient smart grid system. The EMS will send and receive real-time information on power supply and load demand from microgrid. It will provide the basis for all other value-added services such as billing, balance and customer reporting, and network management. Smart grid operators will be able to monitor load demand required and energy generated from DGs measured on halfhourly interval basis and collected by the central server.

\subsubsection{Demand Side Management}

The EMS can provide attractive demand side management (DSM) solutions which (i) enable consumers to monitor and manage their energy consumption according to changes in the energy price and hence achieving energy trading; (ii) shift their usual usage from peak to off-peak periods; (iii) prioritize the way they use energy; and (iv) in doing so, reduce their overall energy costs. Furthermore, if demand can be shifted away from peak periods, power companies will not need to build extra power plants to cope with such high demand requirements, which will ultimately reduce carbon emissions and mitigate climate change. The EMS server runs advanced power applications which analyze measurements from all electrical devices/equipment of consumer premises to arrive at a decision.

\subsubsection{DG Management}

Clean and renewable energy sources are often intermittent in nature. For instance, solar PV modules cannot generate electricity at night or when it is cloudy. The DG management system through EMS is required to monitor and manage DGs to ensure supply stability and optimum output. EMS with the minimum energy trading costs, DG production capability and load consumption determines amount of power the microgrid should draw/transfer from/to other microgrid in a smart grid system. 


\subsubsection{Demand Response Management}

The EMS can interface with building management systems or other electrical management system to facilitate load control and short-term load reduction at the consumer premises during system constraints or periods of maximum demand. In this way, the EMS will shed non-essential loads in buildings such as corridor lighting loads. The EMS can also automatically adjust the temperature of the heating, ventilation and air conditioning system in order to reduce the instantaneous loading on their compressors. This will help level the load on the grid and therefore raise the overall efficiency of the power grid. The demand response (DR) function can help keep the grid in balance when energy supplies get tight, or as more DGs, like PV, wind turbine, and MT come online. Applications are optimization routines which attempt to lower operation cost or maximize profit while enhancing energy efficiency.

\subsubsection{Energy Efficiency System}

The EMS can achieve cost reduction through the rational and efficient use of energy. The EMS interfaces with home automation systems and building management systems for energy efficiency in homes and buildings. This will allow consumers to track and manage the energy usage of appliances and devices in the home that consume energy. The EMS receives real-time price signals from the market operators and relays to "smart" home controllers or end-consumer devices like dish washers, washing machines, and airconditioners. These devices, in turn, will decide whether to operate based on the consumer's instructions. The EMS will allow consumers to easily control the temperature of their premises from a single thermostat or using a more complex combination of multiple thermostats, motorized blinds, and remote temperature sensors. This will ensure energy efficiency and provide a climate control solution that fits consumer's needs accordingly. 


\subsection{Research Motivations}

Currently, most research work on smart grid are focused on the development and application of the smart grid concept. In the worldwide, utilities and governments are looking at energy management system to monitor, control, and optimize the generation, distribution and transmission of energy in order to achieve improvements in grid automation and economic. Various research works have been conducted in [10]- [12] on the design of an EMS to determine the optimal operating condition of microgrids with maximum profit and minimum operating cost. Research on smart grid energy management system in the literature mainly focuses on the solution to optimally schedule production of DERs in a single microgrid to minimize operating cost. However, these research works do not consider the power limits of transmission cables. In this thesis, the optimization algorithm for EMS of smart grid was developed. The advantage of the proposed optimization algorithm is that it takes into account the transmission cable power limit, power losses and available power from the renewable energy sources.

Furthermore, a single microgrid can only generate and distribute power within a localized area. In the event of unavailability/failure of one or more DERs in the single microgrid during islanded mode of operation, the single microgrid itself may not be secure enough to meet its own load demand due to restricted energy generation capability. The additional power can be transferred from other microgrids if they are in adjacent locations and interconnected to supply power to each other. Thus, an EMS is required to monitor, control, and optimize the generation, distribution and transmission of energy for those interconnected microgrids. There is also no significant research in the literature that focuses on the power sharing between interconnected microgrids to ensure security of supply, especially on the energy trading between different microgrids in a smart grid system.

In addition, the infrastructure such as EMS is developed to achieve energy trading between different microgrids in a smart grid system. There has been no research on the cost-benefit analysis of smart grid integration (none in the Singapore context). Many of today's utility 
business models are based upon the utility earning a negotiated return on prudent capital investments. It is not surprising, therefore, that the utilities responsible for making prudent investments focus on minimizing risk. Consequently, utilities are often slow to adopt new technologies that have not been extensively proven outside of a laboratory. In general, the existing utility business model does not provide economic rewards for cutting-edge technologies. In addition, the value of smart grid technologies has been difficult to quantify in a simple cost-benefit analysis due to the multi-tiered benefits they provide to the utility, the consumer, and society. As a smart grid will require significant investment, investors often face the challenges of access to capital to make these investments, as well as the lack of ability to bear the associated costs of the expenses. A smart grid is a complex, comprehensive, and integrated monitoring and operating system; it will provide publicly observable benefits only after considerable investments have been made in upgrading the infrastructure of the nation's utilities and the monitoring and control devices in the homes and businesses of consumers [13].

\subsection{Major Contribution of This Thesis}

1) In line with the above motivations, this thesis presents a hierarchical architecture design for a multi-microgrid using the Multi-Agent System (MAS) concept to be incorporated into the EMS. A three-level hierarchical multi-microgrid design architecture is proposed where large complex control tasks are decomposed into simpler and manageable ones which are then allocated to various intelligent agents to achieve local and global control objectives. The EMS which is the highest-level agent in the multi-microgrid architecture ensures power balance within the smart grid system. This is achieved through energy trading between different microgrids such that total cost is minimized and all operational constraints are satisfied. Mixedinteger linear programming (MILP) is used to determine the optimum solution for the energy management in the smart grid system. The proposed hierarchical architecture design for the multi-microgrid and the developed optimization 
algorithm for the EMS ensure that the smart grid system operates in a coordinated and economic manner. The design concept is demonstrated through different test case scenarios and the results obtained are discussed in this thesis.

2) In addition, the infrastructure such as EMS is successfully developed to achieve energy trading between different microgrids in a smart grid system. The research works also provides a detailed cost-benefit analysis including investment costs, annual savings and payback years for integration of AMI and DR into smart grid. The methodology for the cost-benefit analysis of the smart grid technologies/applications centers on the use of computer models that simulate the specific characteristics and behaviors of the Singapore power grid, with and without certain smart grid technologies being applied. The impacts of the external factors are also included in the simulations.

The research work is conducted in the Clean Energy Research Laboratory at Nanyang Technological University (NTU), Singapore. This laboratory is dedicated to support research projects in the grid integration of clean energy systems from renewable energy sources such as solar and wind. The various simulator and hardware systems especially for the renewable energy sources that are available in the laboratory can be used to obtain accurate data for the cost-benefit analysis of the smart grid system.

\subsection{Organization of This Thesis}

This thesis consists of six chapters as follows:

Chapter 1: Introduction 
This chapter provides the introduction to microgrid, smart grid and energy management including their definition, advantages and applications. It also discusses the motivations and contributions of the research work, as well as the organization of this thesis.

\section{Chapter 2: Literature Review}

This chapter provides a review of previous research works on EMS, including centralized or decentralized control system and MAS. The definition and general formula of MILP and its application for EMS are also discussed. The recent projects about cost-benefit of smart grid are also reviewed in this chapter.

Chapter 3: Design architecture of Smart Grid's Multi-agent System

This chapter provides the description and design architecture for a three-level hierarchical smart grid's multi-agent system formed by three levels of agents. The optimum solution for the EMS to determine the minimum energy trading costs in the smart grid system is also discussed in this chapter.

Chapter 4: Sensitivity Analysis of EMS for Smart Grid's Multi-Agent System

This chapter provides the three different test scenarios on energy trading between different microgrids in a smart grid system. The smart grid system which consists of four single microgrids is used to analyze the proposed EMS for the smart grid.

Chapter 5: Business Case Model of the EMS Integration for Smart Grid's Multi-Agent System

This chapter provides the business case model for EMS integration of smart grid in Singapore. This model will demonstrate the detailed cost-benefit justification for integration of $\mathrm{AMI}$ and $\mathrm{DR}$ to perform the cost-benefit analyses.

Chapter 6: Conclusions and Recommendations for Future Research 
This chapter discuss the overall assessment of the research work and also gives recommendations for future works. 


\section{Chapter 2}

\section{Literature Review}

\subsection{Centralized and Decentralized Model for EMS}

Centralized or decentralized control system is usually adopted for the EMS to ensure that the smart grid operates in a coordinated manner. In a centralized control model, there is one component function as central control unit. It is responsible for collecting, managing, coordinating and making control decisions by analyzing all the measurement data from various equipment. Figure 2-1 illustrates the centralized control concept which can be used as hierarchical control model within the smart grid. The main program at highest level make decision based on load forecasting, state estimation, unit commitment (UC), and economic dispatch (ED). Once the decision made, it will send the corresponding control signal back to the routine for controlling the equipment and devices. In a decentralized control model, there is no central control unit. All individual control units will collect, analyze and make control decisions by themselves. It is a system in which individual control unit operate on local information to accomplish global goals. Different from centralized control, the decision making is based on its own environment. Its behavior will keep changing if environment is changing. Once the decision is made, it will send the corresponding control signal back to itself controlling the equipment and devices.

The implementation of a fully centralized EMS is insufficient to cope with the increasing penetration of DERs as it lacks flexibility and scalability [14], [15]. Similarly, a fully decentralized control system is also not feasible as there must be a minimum level of coordination between the DERs, energy storage devices and loads, which cannot be realized simply by using only locally measured variables [16]. 


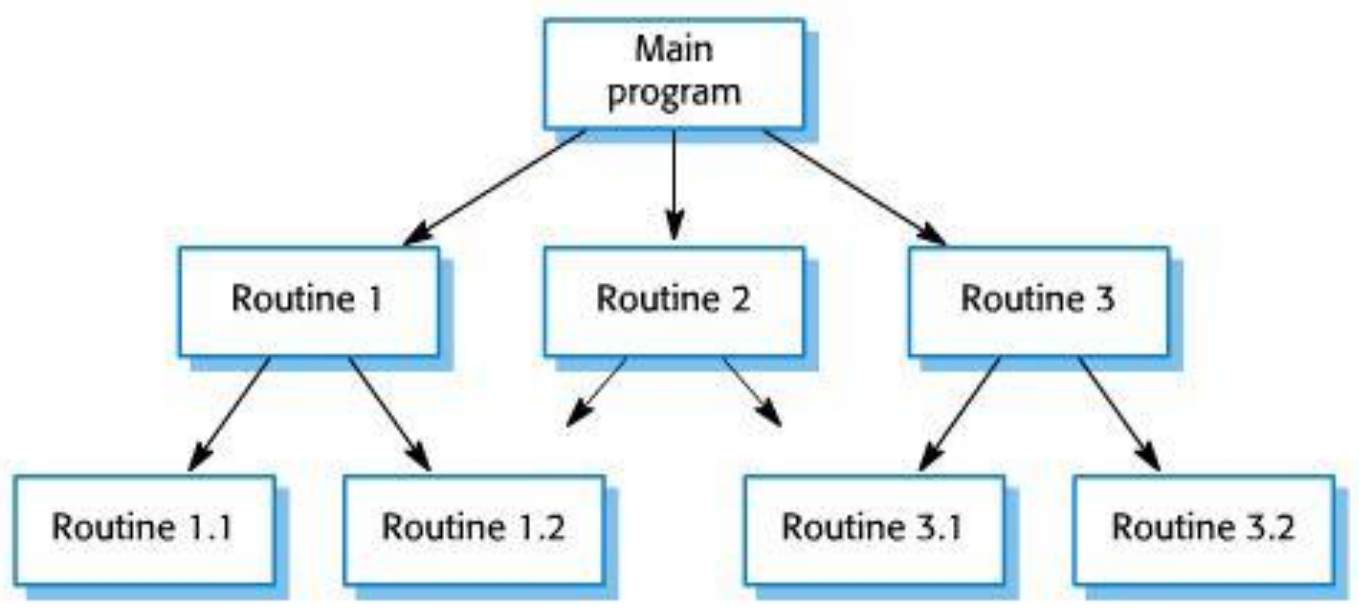

Figure 2-1: Centralized control concept [17].

\subsection{Multi-Agent System}

A MAS is simply a system comprising two or more agents or intelligent agents. It is important to recognize that there is no overall system goal, simply the local goals of each separate agent. The system designer's intentions for the system can only be realized by including multiple intelligent agents, with local goals corresponding to subparts of that intention. Depending on the definition of agency adhered to, agents in a multi-agent system may or may not have the ability to communicate directly with each other. However, under Wooldridge's definitions, intelligent agents must have social ability and therefore must be capable of communication with each other [18]. The main objective of MAS is to decompose large complex control tasks into simpler and manageable ones which are then allocated to various intelligent agents to achieve local and global control objectives and also it has the capability to handle a multi-objective and multi-constraint complex system. It will be used when the application requires many parts that all need to be active at the same time, do not have a single solution space and do not require a centralized control. Since data and information are scattered and decentralized in a microgrid, failure of any control component under MAS distributed control will not threaten the operation of the 
entire microgrid [19]. MAS control also has desirable features such as system openness and scalability which make microgrid control flexible.

Figure 2-2 illustrates how MAS implements distributed decentralized control by the usage of agents. In this hierarchical control architecture, individual agent is able to take some action based on changes in its environment. It also will dynamically change its behavior in order to achieve its goals. For example, if a microgrid agent loses one DER it is unable to meet the total energy output requirement. And then it will search for another agent that provides the same services. Furthermore, agents are able to interact with other agents in order to share necessary data as well as report the operation status. The highest-level agent provides essential communication services such as Agent Management System (AMS) and Directory Facilitator (DF) for agents to communicate and negotiate with each other. In addition, it can also provide monitoring and ancillary services depending on the requirements and specifications of the microgrid.

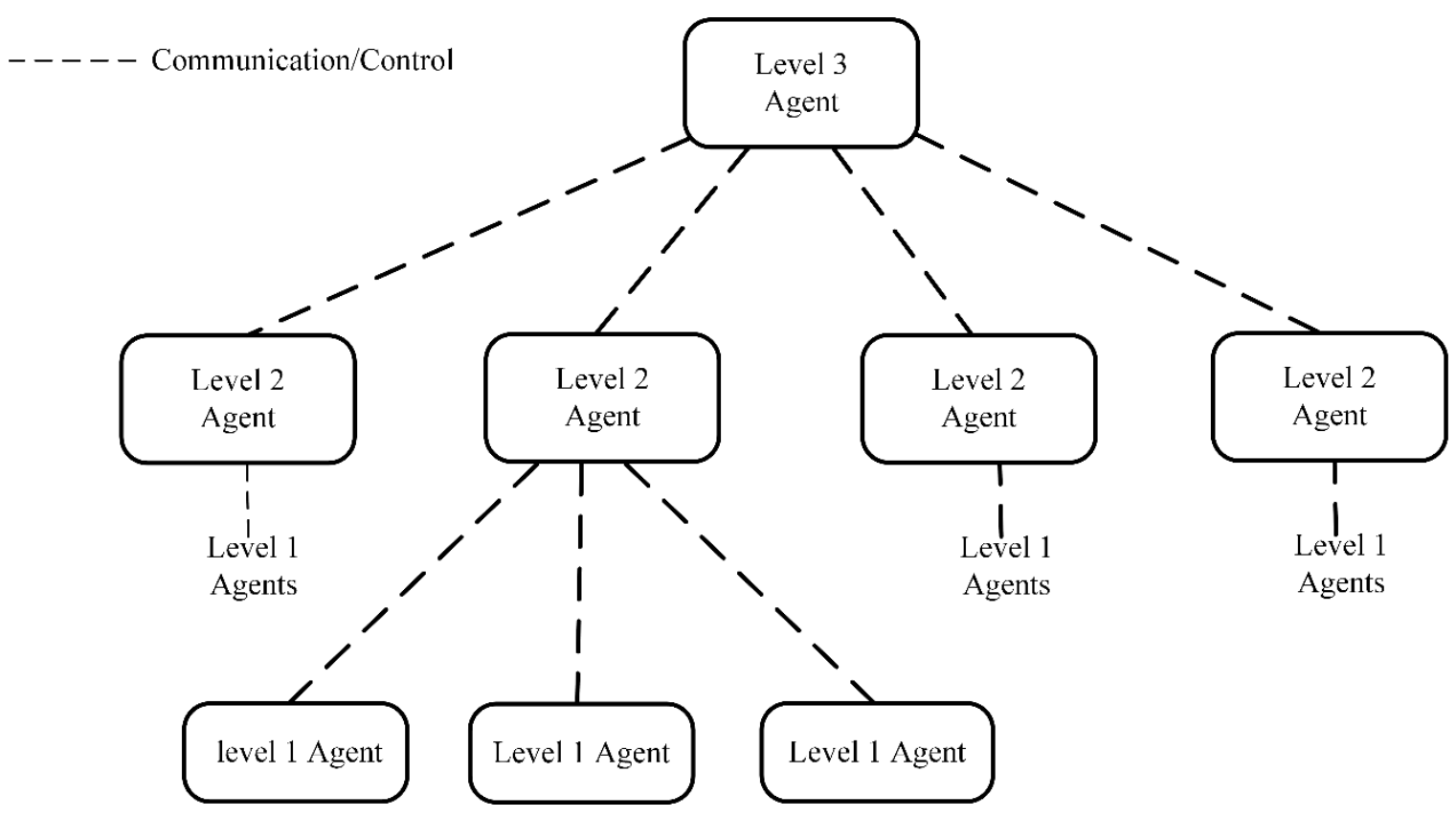

Figure 2-2: MAS control architecture. 
In [20], a pure MAS control concept is proposed for decentralized control of microgrids. The control objectives of the microgrid EMS that are usually pursued to achieve an economical microgrid operation are to minimize the operating costs and maximize the revenue of the microgrid. Therefore, the management of energy is usually formulated into a multi-objective optimization problem and different techniques have been proposed in several research works. In [21] and [22], investigations on pareto optimal solutions using particle swarm optimization and ant colony optimization techniques have been proposed respectively while a weighted objective function that combines different individual objective functions together with heuristics optimization techniques is proposed in [23][25]. There are also research works in the literature that focus on the control methodology of multi-microgrids [26]- [28], however, there is no research on a three-level hierarchical multi-microgrid architecture design based on MAS concept with mixed-integer linear programming (MILP) optimization to achieve energy management objectives for the smart grid system. The MILP optimization algorithm ensures that the total load demand can meet with minimum energy cost. The proposed algorithm considers the available power from DERs, costs of DER energy generation and DR, transmission cable power loss and power limit in determining the optimal power transfer between different microgrids.

\subsection{Mixed-integer linear programming}

MILP is an optimization method that combines continuous and discrete variables. It can be used for creating model complex planning and control problem involving both continuous and discrete decisions. In many settings, the term refers to integer linear programming (ILP), in which the objective function and the constraints (other than the integer constraints) are linear [29].

MILP is defined as below:

$\min c^{T} x$

Subject to $A x=b, x \geq 0, x_{i} \in Z$ 
The problem is that with only some of the variables are constrained to be integers while other variables are allowed to be non-integers in MILP.

\subsection{Energy Management of Smart Grid}

According to the latest research, the main area of studying for the energy management of smart grid is the problem to optimally schedule internal production by DERs in order to minimize microgrid's operating cost such as fuel cost, startup cost and maintenance cost. The UC and the ED have been successfully applied to the solution of optimally scheduled problem in order to achieve power balance of the microgrid with minimized operation cost, where UC determines when should each DER start/stop and ED determines how much power will produced by each DERs. However, the UC and ED does not take into account power cable transmission limit and the optimization is only applied to the localized area. Thus, both are not suitable for EMS of smart grid.

In case of weekdays, low demand of residential load will result in large surplus power from the PVs. It will cause the inefficient use of energy if the energy is not fully utilized by the loads. To overcome this problem, [30] proposed the energy storage system to store the excess power. However, the setup cost of the proposed energy storage system is high, such that it is hard to compete with the current utility power. In this thesis, the proposed optimization algorithm of EMS for smart grid concept will allow the surplus power to be fully utilized by transferring power for microgrids to the maximizing overall energy efficiency.

\subsection{Recent Project of Smart Grid Cost-Benefit Analysis}

In Singapore, the Energy Market Authority (EMA) launched a $\$ 30$ million pilot project for an "Intelligent Energy System" (IES) [31]. The project will test a range of smart grid technologies to enhance the capabilities of Singapore's power grid infrastructure. The IES project will involve around 4,500 customers in various residential, commercial and 
industrial locations, including NTU's campus, the CleanTech Park at Jalan Bahar and the Punggol Eco-Precinct. The IES pilot project will be conducted in two phases. Phase 1 (2010-2012) will focus on the implementation of the enabling infrastructure for the IES while Phase 2 (2012-2013) will focus on the smart grid applications [31]. However, there have been very few research works (none in the Singapore context) addressing the realistic conditions for implementing the smart grid concept. The Electricity Advisory Committee (EAC) of the United States Department of Energy (DOE) conducted a study "Smart Grid: Enabler of the New Energy Economy" in 2008 that discusses both the opportunities and challenges in transforming its electric power delivery system to an intelligent smart grid as well as the benefits of moving to a more intelligent grid including the potential economic and environmental payoffs [13]. Besides governments, utilities also are actively involved in cost-benefit analysis of smart grid system. The Northeast Utilities, that operates New England's largest utility system serving customers in Connecticut, western Massachusetts and New Hampshire, proposed a study "Plan-It Wise Energy Pilot" in 2009. The study aims to identify the economic parameters in which AMI and smart grid will be cost effective, identify the benefits associated with each capability and illustrate cost effectiveness of each capability [32]. 


\section{Chapter 3}

\section{Design architecture of Smart Grid's Multi-Agent System}

\subsection{Introduction}

The smart grid concept offers customers increased reliability and quality in the service provided by system operator. The reduction in emissions and energy losses also make the smart grid a promising alternative to traditional power distribution systems. However, the design of a smart grid architecture that provides an efficient operation and control of the smart grid poses a challenging problem. A single microgrid can only generate and distribute power within a localized area. Furthermore, in the event of unavailability/failure of one or more DERs in the single microgrid during islanded mode of operation, the single microgrid itself may not be secure enough to meet its own load demand due to restricted energy generation capability. Additional power is required to meet the increase in load demand. In this chapter, instead of power transferred from the utility grid, the additional power will be transferred from other microgrids in which they are located in adjacent areas and they are interconnected to supply power to each other under smart grid's multi-agent system concept.

In this chapter, the design architecture for a three-level hierarchical smart grid's multi-agent system is formed by three levels of agents, namely, level 1 agents (load and DER agents), level 2 agents (microgrid agents) and level 3 agent (smart grid agent) as presented in Fig. 3-1. This thesis considers PV and MT as the main DERs for a single microgrid considering that Singapore has strong sunlight with an average irradiation of around $4.2 \mathrm{kWh} / \mathrm{m} 2 / \mathrm{day}$ [33] and the liquefied natural gas (LNG) terminal has been made available starting from May 2013 [34]. 


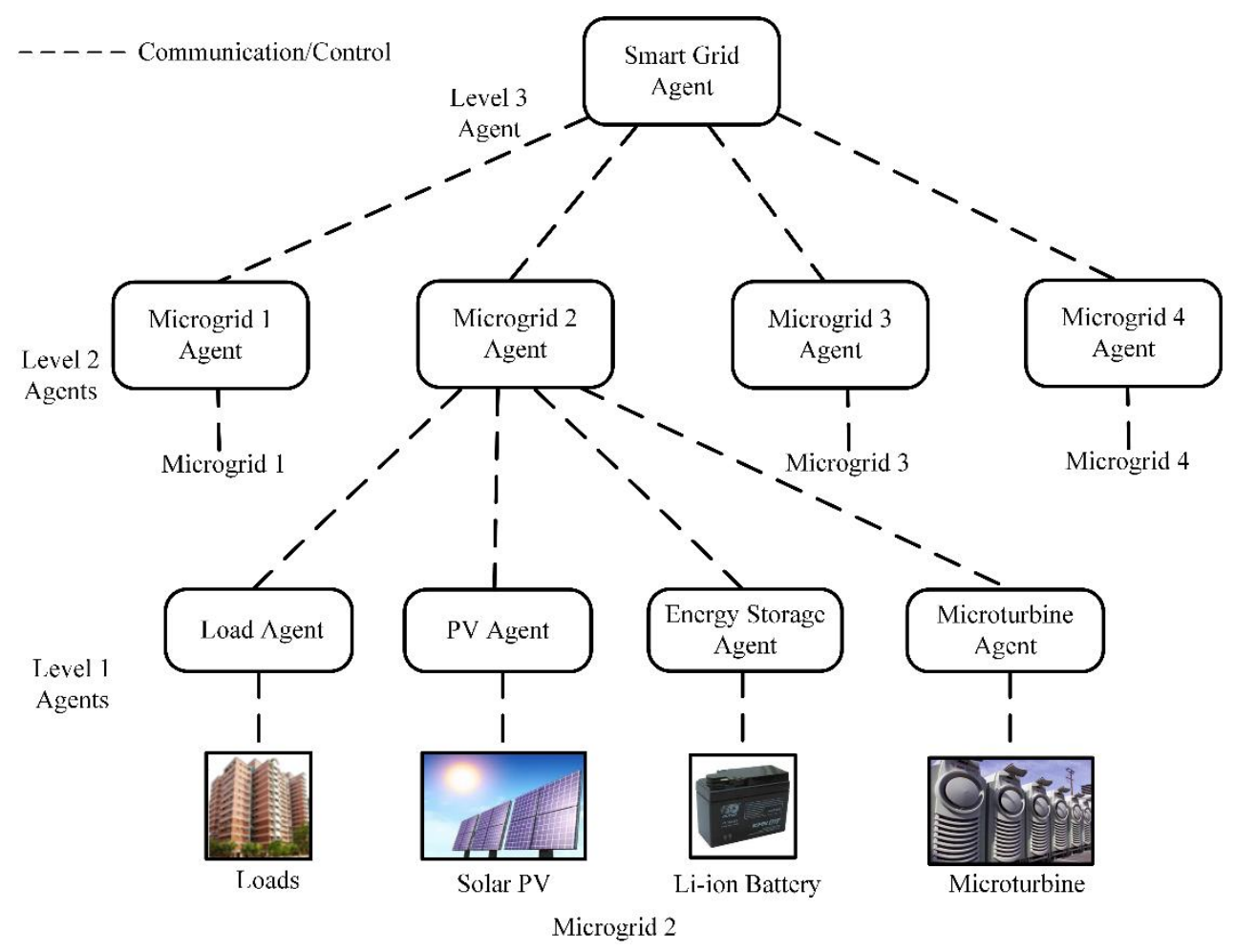

Figure 3-1: Proposed three-level hierarchical smart grid architecture design.

\subsection{Multi-Agent System Description}

a) Level 1 Agents: The level 1 agents of the proposed multi-microgrid hierarchical architecture consist of DERs and load agents which are managed by level 2 microgrid agents. These level 1 agents have the capability to operate autonomously based solely on local measurements from the DERs and loads. The load agent is responsible for controlling the on/off status of the loads. Upon receiving load shifting and curtailment commands, demand side management and DR programs can be executed during peak demand periods and islanded mode of operation, respectively. The responsibility of the DER agents is to regulate the output power, voltage and frequency of each DER through their inverter system, and maximize their power generation during grid-connected and islanded modes of operation. There are a lot of research work conducted on the control of power electronics interfaced DER in microgrids and these controllers are usually implemented using synchronous reference frame $(d q)$ control [35], stationary reference frame $(\alpha \beta)$ control [36], 
and natural frame $(a b c)$ control [37]. As the focus of the research work is not on the level 1 agent, it is assumed that the controller design of DER inverters in each microgrid is based on existing controller in the literature.

b) Level 2 Agents: The level 2 microgrid agents are responsible for reporting to the level 3 smart grid agent the amount of excess power available from their DERs or the amount of additional power required from other microgrids to serve their own load demand. More specifically, the level 2 microgrid agents will provide the amount of excess/required power, the amount of power generated by DERs, the amount of loads that can be shed and their associated costs. The amount of power generated by DERs and the total load demand are determined based on generation and load forecasting algorithms, respectively. During gridconnected operation, the distribution grid is connected to the microgrid. The role of the level 2 microgrid agents functions to provide local power and voltage support for the loads and hence reduce the burden of generation and delivery of power directly from the distribution grid. During islanded mode of operation, the distribution grid is disconnected from the microgrid and the DERs are the sole power sources left to regulate the loads. In this case, the level 2 microgrid agents function to optimally manage the DER generation capacity to meet the total load demand in order to maintain the power balance and stability of the microgrid. When the total load demand exceeds the generation capacity of the DERs, load shedding for non-critical loads will be performed to restore the system frequency and maintain the stability of the microgrid.

The microgrid operates on constraints such as the state-of-charge (SoC) of the energy storage device and the start-up time of each DER. Based on these operating constraints, each level 2 microgrid agent performs optimization at the microgrid level using information on the forecasted load demand, electricity pricing at peak and off-peak periods, peak shaving, load curtailment and network congestion to provide on/off status for the load agents and power, voltage and frequency set points for the DER agents. In this thesis, it is assumed that level 2 microgrid agents utilize the method proposed in [38] to coordinate the 
operations of the different loads and DERs in a single microgrid for efficient energy management in both grid-connected and islanded modes of operation.

The cost of PV energy generation $\lambda^{P V}$ in dollars per $\mathrm{kWh}$ is calculated based on the Levelized Cost of Energy (LCOE). The LCOE is defined as the sum of all costs incurred over the lifetime of a given generating technology divided by the energy produced over its lifetime as given by [39]

$$
\lambda^{P V}=\frac{\sum_{y=1}^{Y} \frac{I_{y}+M_{y}}{(1+r)^{y}}}{\sum_{y=1}^{Y} \frac{E_{y}}{(1+r)^{y}}}
$$

where $Y$ is the expected payback year, $I_{y}$ is the investment expenditure in the $y^{\text {th }}$ year, $M_{y}$ is the operation and maintenance cost in the $y^{\text {th }}$ year, $r$ is the annual effective discount rate and $E_{y}$ is the total energy production of the PV system in the $y^{\text {th }}$ year.

The fuel cost of MT energy generation $\lambda^{M T}$ in dollars per hour is represented by a quadratic polynomial function of the microturbine output power in the form [11]

$$
\lambda^{M T}=a+b P_{M T}+c P_{M T}^{2}
$$

where $P_{M T}$ is the output power of the MT, and $a, b$ and $c$ are constant coefficients in $\$ / \mathrm{hr}$, \$/MWhr and \$/MW' ${ }^{2} \mathrm{hr}$, respectively.

The cost of demand response $\lambda^{D R}$ is calculated based on the value of the load without demand response and the amount of energy reduced with demand response. The cost of demand response in dollars per $\mathrm{kWh}$ is then given by 


$$
\lambda^{D R}=\frac{\sum_{i=1}^{m} C_{i}}{\Delta T \times \sum_{i=1}^{m} P_{i}}
$$

where $m$ is the number of loads to be shed, $C_{i}$ is the value of the load $i$ without demand response, $\Delta T$ is the time interval in hours and $P_{i}$ is the power demand of load $i$.

It is assumed that the costs of DER energy generation and demand response, i.e., $\lambda^{P V}, \lambda^{M T}$ and $\lambda^{D R}$ are constant throughout one time interval but may change in the next time interval according to the weather condition, fuel cost, grid electricity tariff and load demand.

c) Level 3 Agent: The level 3 smart grid agent shown in Figure 3-1 is the highest control level in the hierarchical architecture design. The main responsibility of the level 3 smart grid agent is to coordinate, control and optimize the power flow operation of multiple microgrids with the distribution grid by exchanging necessary information on power generation, load demand and energy costs. The level 3 smart grid agent will intelligently manage the power flow among the four microgrids according to the power set points which are optimized by MILP algorithm. It will balance shortage and surplus of power for each microgrid as well as achieve global optimization. Finally, it is to ensure the stability and security of power supply during system contingencies such as loss of DER or shortage of power supply during islanded mode of operation. When a power shortage occurs in a single microgrid during islanded mode of operation, it can draw power from adjacent microgrids to meet its load demand, which is the key advantage of a multi-microgrid. This proposed network topology of interconnection between adjacent microgrid ensures better supply security. In addition, it can efficiently provide better frequency regulation and load following for accommodating temporary load variations.

Based on the information provided by each level 2 microgrid agent on their amount of excess/required power, the amount of power generated by DERs, amount of loads that can 
be shed and their associated costs, and the smart grid agent functions as EMS to perform optimization at the smart grid level in order to achieve the following key objectives:

i) providing power set points and power flow directions to level 2 microgrid agents;

ii) ensuring the total load demand of each microgrid being met with minimum cost;

iii) ensuring maximum utilization of DERs excess generation;

iv) reducing energy import from the electricity grid;

v) minimizing line losses by optimizing the power flow within the smart grid system;

vi) achieve the overall efficient energy management.

In order to solve the optimization problem, the EMS objectives are reformulated into a MILP optimization problem. The flowchart of the optimization algorithm is shown in Figure 3-2. At the beginning of each time interval, based on the information provided by level 2 microgrid agents, the algorithm will determine whether the total PV generation in $N$ microgrids is equal to the total load demand in $N$ microgrids. If yes, then the algorithm determines the amount of PV power that needs to be transferred between different microgrids in the case when one microgrid has excess PV generation while the other has shortage of PV generation. There will not be any power transfer between the microgrids if each microgrid can supply its own load demand using its own PV generation. However, if the total PV generation is not equal to the total load demand in the smart grid system, the algorithm will then determine whether the total PV generation is greater or lower than the total load demand in the smart grid system. In the case when the total PV generation is greater than the total load demand, the excess PV generation will be used to charge the energy storage devices in the microgrids with excess PV generation. In this thesis, it is assumed that the energy storage devices always have sufficient capacity to be charged. In the case when the total PV generation is lower than the total load demand of the smart grid system, the optimization algorithm will determine the optimum power set points for each microgrid and the direction of power transfer that will achieve the minimum total energy trading cost $C_{T E T}$ and satisfy the power transfer constraints. 
In the grid-connected mode of operation, additional power required by each microgrid will be supplied by the electricity grid as the grid energy price will be lower than the microturbine energy generation cost. Meanwhile, in the islanded mode of operation, the MT takes the primary role to supply additional power required by each microgrid. In the worst case when the MT is not able to meet the total load demand or the MT power cannot be transferred to the load due to the transmission cable power limit, the algorithm will determine the optimum amount of load shedding to reduce the total load demand requirement. For all the cases, the cable that has the lowest power losses will be used first to minimize the power losses. 


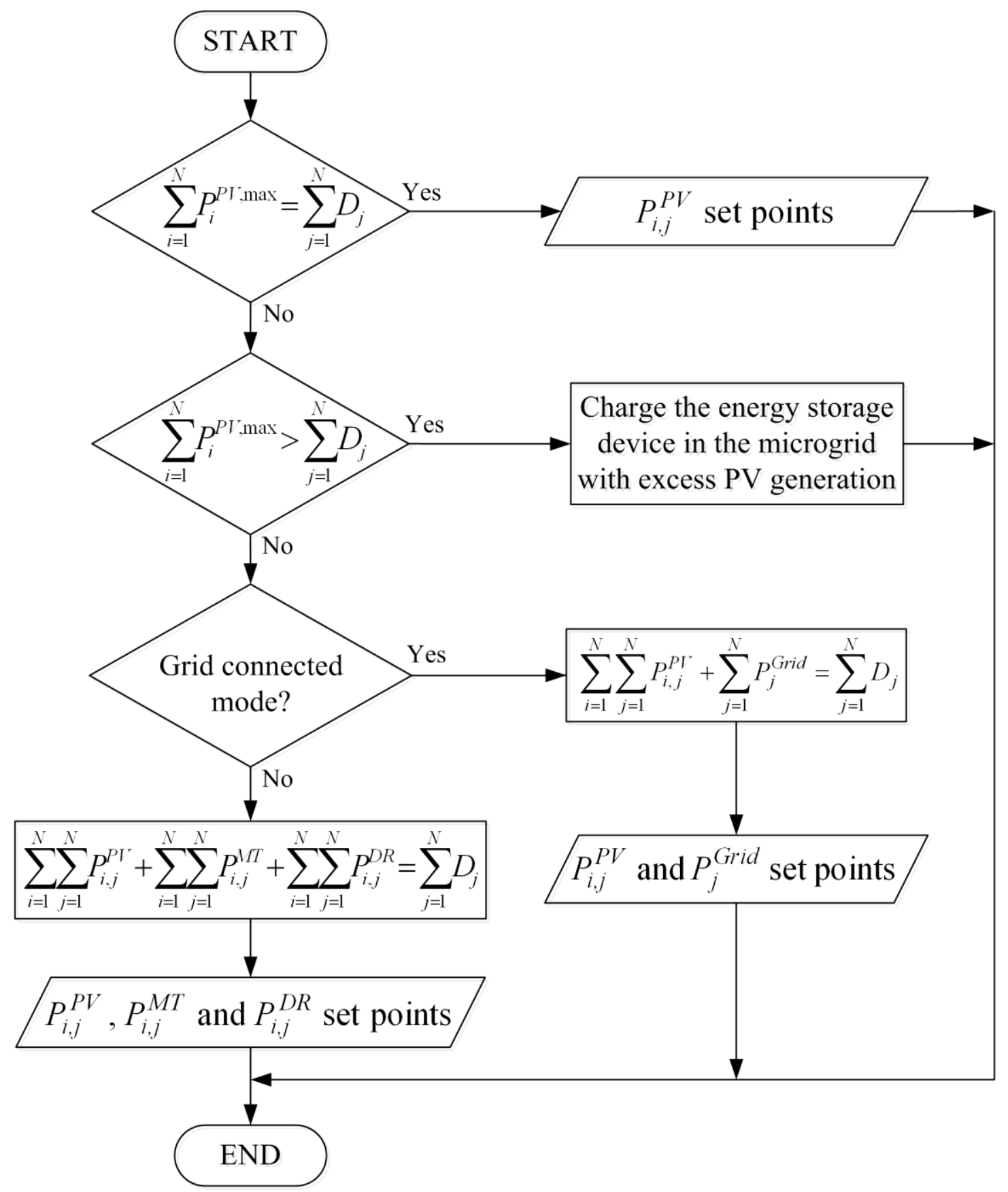

Figure 3-2: Flowchart of the proposed optimization algorithm 


\subsection{MILP Problem Formulation of EMS for Smart Grid}

This section presents the mathematical formulation for the MILP optimization problem of the EMS for the three-level hierarchical smart grid system. The main objective of the EMS is to maintain the supply and demand balance in the smart grid system during each time interval with minimum $C_{T E T}$. Therefore, the objective function of the optimization is to minimize the energy cost as given by

$$
\operatorname{Min} \mathrm{C}_{\mathrm{TET}}=C_{P V}+C_{M T}+C_{D R}+C_{\text {Grid }}
$$

where

$$
\begin{aligned}
& C_{P V}=\Delta T \sum_{i=1}^{N} \sum_{j=1}^{N}\left[P_{i, j}^{P V}(k) \cdot \lambda_{i}^{P V}(k)\right] \\
& C_{M T}=\Delta T \cdot \lambda_{i}^{M T}\left(P_{i, \text { total }}^{M T}\right) \\
& C_{D R}=\Delta T \sum_{i=1}^{N} \sum_{j=1}^{N}\left[P_{i, j}^{D R}(k) \cdot \lambda_{i}^{D R}(k)\right] \\
& C_{\text {Grid }}=\Delta T \sum_{j=1}^{N}\left[P_{j}^{\text {Grid }}(k) \cdot \lambda^{\text {Grid }}(k)\right] \\
& P_{i, \text { total }}^{M T}(k)=\sum_{i=1}^{N} \sum_{j=1}^{N} P_{i, j}^{M T}(k)
\end{aligned}
$$

subject to

$$
\sum_{i=1}^{N} \sum_{j=1}^{N}\left[P_{i, j}^{P V}(k)+P_{i, j}^{M T}(k)+P_{i, j}^{D R}(k)\right]+\sum_{j=1}^{N} P_{j}^{G r i d}(k)=\sum_{j=1}^{N} D_{j}(k)+\sum_{i=1}^{N} \sum_{j=1}^{N} P_{i, j}^{L}(k)
$$




$$
\begin{aligned}
& 0 \leq \sum_{j=1}^{N} P_{i, j}^{P V}(k) \leq P_{i}^{P V, \max }(k) \\
& x\left(P_{i}^{M T, \min }\right) \leq \sum_{j=1}^{N} P_{i, j}^{M T}(k) \leq x\left(P_{i}^{M T, \max }\right) \\
& 0 \leq \sum_{j=1}^{N} P_{i, j}^{D R}(k) \leq P_{i}^{D R, \max }(k) \\
& 0 \leq P_{i, j}^{P V}(k)+P_{i, j}^{M T}(k)+P_{i, j}^{D R}(k) \leq P_{i, j}^{\max }
\end{aligned}
$$

where $C_{P V}, C_{M T}, C_{D R}$ and $C_{G r i d}$ are the total energy cost of PV, MT, DR and electricity grid, respectively. $N$ is the total number of microgrids in the smart grid system, and $k$ represents each half-hour interval in a day which takes the values of $1,2,3, \ldots, 48 . P_{i, j}^{P V}(k), P_{i, j}^{M T}(k)$ and $P_{i, j}^{D R}(k)$ are the total amount of power transferred from PV, MT and DR from microgrid $i$ to microgrid $j$ at time interval $k$, while $P_{j}^{\text {Grid }}(k)$ is the amount of power purchased by microgrid $j$ from the electricity grid at time interval $k . \lambda^{\text {Grid }}(k)$ is the energy price of the electricity grid at time interval $k$ and $D_{j}(k)$ is the total amount of load demand of microgrid $j$ at time interval $k . P_{i}^{P V, \max }(k), P_{i}^{M T, \max }(k)$ and $P_{i}^{D R, \max }(k)$ are the maximum available power of PV, MT and DR of $i^{\text {th }}$ microgrid at time interval $k . P_{i}^{M T, \min }(k)$ is the minimum operation power of the MT at time interval $k . x$ is a binary variable which takes the value of 1 if the MT is supplying power at time interval $k$, else $0 . P_{i, j}^{\max }$ is the maximum power that can be transferred from microgrid $i$ to microgrid $j$ due to transmission cable power limit. $P_{i, j}^{L}(k)$ is the transmission cable power loss incurred due to power transfer from microgrid $i$ to microgrid $j$ at time interval $k . P_{i, j}^{L}(k)$ is given by 
$P_{i, j}^{L}(k)=\left(\frac{P_{i, j}^{P V}(k)+P_{i, j}^{M T}(k)}{\sqrt{3} V_{i, j} \cos \varphi}\right)^{2} \cdot R_{i, j}^{C}$

where $V_{i, j}$ is the transmission line voltage between microgrid $i$ and microgrid $j, \cos \varphi$ is the power factor and $R_{i, j}^{C}$ is the transmission cable resistance of microgrid $i$ and microgrid $j$.

$C_{T E T}$ given in (3.4) is obtained from the total cost summation of all power transferred from the electricity grid, DERs and DR between the microgrids in the smart grid system to meet the total load demand. Equations (3.5), (3.6), (3.7) and (3.8) calculate the cost of energy supplied from PV, MT, DR and electricity grid, respectively. The overall power balance constraint represented by (3.10) in the smart grid level ensures that the total amount of power from the electricity grid, DERs and DR meets the total load demand requirement of the smart grid system. Equations (3.11), (3.12) and (3.13) are the constraints to ensure that the amount of power transferred from PV, MT and DR does not exceed their available power at time interval $k$, respectively. Finally, (3.14) gives the constraint to ensure that the transmission cable power limit of the line connecting microgrid $i$ to microgrid $j$ is not violated.

The results of the optimization algorithm will provide the power set points for the electricity grid, DERs and DR as well as the power flow direction, e.g., from microgrid $i$ to microgrid $j$, with minimum $C_{\text {TET }}$. In addition, this thesis proposes a market clearing price $\lambda_{m m}$ for the total amount of power transferred within the smart grid system which can be calculated based on the $C_{T E T}$ and the total power supplied as given by (3.16). The market clearing price $\lambda_{m m}$ is used as the base price for all energy transaction at the smart grid level. This means that the microgrids with additional load demand will buy the electricity from the level 3 smart grid agent at the market clearing price while the microgrids with excess generation will sell their energy to the level 3 smart grid agent at the market clearing price. 


$$
\lambda_{\mathrm{mm}}=\frac{C_{T E T}}{\Delta T\left(\sum_{i=1}^{N} \sum_{j=1}^{N}\left[P_{i, j}^{P V}(k)+P_{i, j}^{M T}(k)+P_{i, j}^{D R}(k)\right]+\sum_{j=1}^{N} P_{j}^{\text {Grid }}(k)\right)}
$$

\subsection{Summary}

In this section, a three-level hierarchical smart grid multi-agent system was proposed and the three levels of agents were introduced. The proposed smart grid system with multimicrogrid architecture design shown in Figure 3-1 is formed by four single microgrid systems as an example to introduce the design concept. Multiple microgrids in adjacent locations are then interconnected to exchange power with each other to ensure improved security of supply in the smart grid system. This multi-microgrid architecture will significantly reduce the amount of electrical energy imported from the electricity grid and thus contribute significantly to the reduction of greenhouse gas emissions and the mitigation of climate change. Furthermore, this network topology can be seamlessly scaled up to interconnect more microgrids. 


\section{Chapter 4}

\section{Sensitivity Analysis of EMS for Smart Grid's Multi-Agent System}

\subsection{Introduction}

A three-level hierarchical smart grid multi-agent system and the mathematical formulation for the MILP optimization problem of the EMS for the three-level hierarchical smart grid system has been introduced in Chapter 3. In this chapter, the three different test scenarios on energy trading between different microgrids in a smart grid system is used to demonstrate the design concept of the three-level hierarchical smart grid system adopted for the proposed EMS. The MILP is used to determine the optimum solution for the energy distribution in the multi-microgrid system. The following test case scenarios are studied:

Test Case 1: Grid-connected mode of operation and the total amount of PV energy generation is insufficient to supply the total load demand.

Test Case 2: Islanded mode of operation and the total amount of PV energy generation is insufficient to supply the total load demand. The total load demand is same as Test Case 1. Test Case 3: Islanded mode of operation and the total amount of PV energy generation is insufficient to supply the total load demand. The total load demand is higher than Test Cases 1 and 2.

The transmission cable power limits and transmission cable power losses used in all three test case studies for power transfer between different microgrids in the multi-microgrid are given in Table 4.1. In this thesis, only active power loss of transmission cable is considered for three test cases. It is assumed that the parameters associated with different DERs and DR in each microgrid including the energy generation costs, maximum power output and maximum shedding capacities are provided by Level 2 microgrid agents as given in Table 
4.2. The transmission line voltage and power factor are assumed as $6.6 \mathrm{kV}$ and 0.8 , respectively. The electricity grid tariff and time interval are set as $\$ 0.2518 / \mathrm{kWh}[40]$ and 30 minutes respectively to follow the electricity tariff and energy trading interval in Singapore. The MILP optimization problem formulated in the previous section is implemented using MATLAB R2012b with solver IBM ILOG'S CPLEX V12.6 [41].

Table 4.1 Transmission cable power limits and resistances

\begin{tabular}{|c|c|c|c|}
\hline & $\begin{array}{c}\text { Cable Power Limit } \\
(\mathrm{kW})\end{array}$ & $\begin{array}{c}\text { Cable Resistance } \\
(\Omega / \mathrm{km})\end{array}$ & $\begin{array}{c}\text { Cable Length } \\
(\mathrm{km})\end{array}$ \\
\hline $\mathrm{MG}_{1} \leftrightarrow \mathrm{MG}_{2}$ & 300 & 0.576 & 10 \\
\hline $\mathrm{MG}_{1} \leftrightarrow \mathrm{MG}_{3}$ & 350 & 0.426 & 10 \\
\hline $\mathrm{MG}_{1} \leftrightarrow \mathrm{MG}_{4}$ & 320 & 0.576 & 10 \\
\hline $\mathrm{MG}_{2} \leftrightarrow \mathrm{MG}_{3}$ & 230 & 0.426 & 10 \\
\hline $\mathrm{MG}_{2} \leftrightarrow \mathrm{MG}_{4}$ & 360 & 0.799 & 10 \\
\hline $\mathrm{MG}_{3} \leftrightarrow \mathrm{MG}_{4}$ & 290 & 0.576 & \\
\hline
\end{tabular}

Table 4.2 DER and demand response parameters from level 2 microgrid agents

\begin{tabular}{|c|c|c|c|c|c|c|c|c|c|}
\hline & \multicolumn{2}{|c|}{ PV } & \multicolumn{5}{c|}{ MT } & \multicolumn{2}{c|}{ DR } \\
\cline { 2 - 10 } & $\begin{array}{c}\lambda^{P V} \\
(\$ / \mathrm{kWh})\end{array}$ & $\begin{array}{c}P_{i}^{P V, \max } \\
(\mathrm{kW})\end{array}$ & $\begin{array}{c}P_{i}^{M T, \min } \\
(\mathrm{kW})\end{array}$ & $\begin{array}{c}P_{i}^{M T, \max } \\
(\mathrm{kW})\end{array}$ & $\mathrm{a}$ & $\mathrm{b}$ & $\mathrm{c}$ & $\begin{array}{c}\lambda^{D R} \\
(\$ / \mathrm{kWh})\end{array}$ & $\begin{array}{c}P_{i}^{D R, \max } \\
(\mathrm{kW})\end{array}$ \\
\hline $\mathrm{MG}_{1}$ & 0.124 & 350 & 35 & 300 & 1.07 & 0.3213 & 0.0016 & 0.863 & 110 \\
\hline $\mathrm{MG}_{2}$ & 0.132 & 400 & 16.4 & 340 & 1.12 & 0.3311 & 0.0015 & 0.881 & 97 \\
\hline $\mathrm{MG}_{3}$ & - & - & 16 & 410 & 1.06 & 0.3263 & 0.0011 & 0.854 & 70 \\
\hline $\mathrm{MG}_{4}$ & - & - & 20 & 430 & 1.07 & 0.3121 & 0.0012 & 0.846 & 130 \\
\hline
\end{tabular}

\subsection{Test Case 1: Grid-Connected Mode of Operation with Insufficient Energy Generation from PV}


In this test case study, level 2 agents of microgrid $1\left(\mathrm{MG}_{1}\right)$ and microgrid $2\left(\mathrm{MG}_{2}\right)$ report excess PV generation of 350kW and 400kW, respectively; while level 2 agents of microgrid $3\left(\mathrm{MG}_{3}\right)$ and microgrid $4\left(\mathrm{MG}_{4}\right)$ require load demand of $980 \mathrm{~kW}$ and $870 \mathrm{~kW}$, respectively. Therefore, at the multi-microgrid level, the total amount of PV generation of $750 \mathrm{~kW}$ from $\mathrm{MG}_{1}$ and $\mathrm{MG}_{2}$ is insufficient to supply the total load demand requirement of $1,850 \mathrm{~kW}$ for $\mathrm{MG}_{3}$ and $\mathrm{MG}_{4}$. Therefore, the power shortage of $1,100 \mathrm{~kW}$ must be supplied from other sources in the smart grid system. The proposed optimization algorithm is employed to obtain the optimal power transfer set points to fully utilize the excess PV power and cater for the power demand of $\mathrm{MG}_{3}$ and $\mathrm{MG}_{4}$ with consideration of the transmission cable power limits and transmission losses.

Table 4.3 Numerical results for test case 1

\begin{tabular}{|c|c|c|c|c|c|}
\hline Power Flow & $\begin{array}{c}\mathrm{PV} \\
(\mathrm{kW})\end{array}$ & $\begin{array}{c}\mathrm{MT} \\
(\mathrm{kW})\end{array}$ & $\begin{array}{c}\mathrm{DR} \\
(\mathrm{kW})\end{array}$ & $\begin{array}{c}\text { Grid } \\
(\mathrm{kW})\end{array}$ & $\begin{array}{c}\mathrm{P}_{\text {loss }} \\
(\mathrm{kW})\end{array}$ \\
\hline $\mathrm{MG}_{1} \rightarrow \mathrm{MG}_{3}$ & 350 & - & - & - & 6.24 \\
\hline $\mathrm{MG}_{2} \rightarrow \mathrm{MG}_{3}$ & 230 & - & - & - & 2.69 \\
\hline $\mathrm{MG}_{3} \rightarrow \mathrm{MG}_{3}$ & - & - & - & - & - \\
\hline $\mathrm{MG}_{4} \rightarrow \mathrm{MG}_{3}$ & - & - & - & - & - \\
\hline $\mathrm{Grid} \rightarrow \mathrm{MG}_{3}$ & - & - & - & 408.93 & - \\
\hline $\mathrm{MG}_{1} \rightarrow \mathrm{MG}_{4}$ & - & - & - & - & - \\
\hline $\mathrm{MG}_{2} \rightarrow \mathrm{MG}_{4}$ & 170 & - & - & - & 2.76 \\
\hline $\mathrm{MG}_{3} \rightarrow \mathrm{MG}_{4}$ & - & - & - & - & - \\
\hline $\mathrm{MG}_{4} \rightarrow \mathrm{MG}_{4}$ & - & - & - & - & - \\
\hline $\mathrm{Grid}_{\mathrm{M}} \rightarrow \mathrm{MG}_{4}$ & - & - & - & 702.76 & - \\
\hline
\end{tabular}




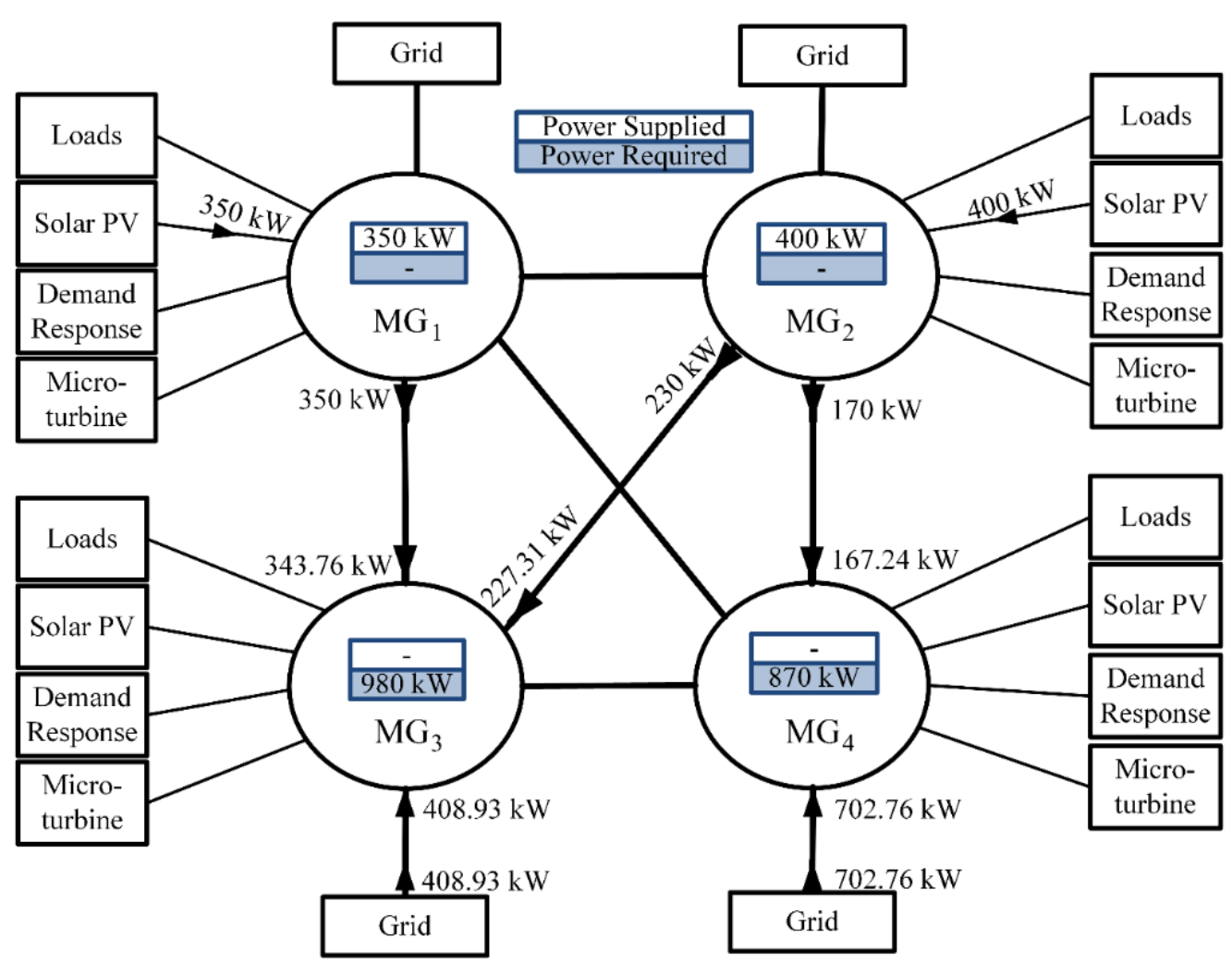

Figure 4-1: Test Case 1: Power supplied to microgrids with load demand.

The numerical results of the optimization algorithm for Test Case 1 are shown in Table 4.3 and are also graphically represented in Figure 4-1. Firstly, it can be observed from Table 4.3 that the excess PV generation from $\mathrm{MG}_{1}$ and $\mathrm{MG}_{2}$ is fully utilized where $350 \mathrm{~kW}$ from $\mathrm{MG}_{1}$ is transferred to $\mathrm{MG}_{3}, 230 \mathrm{~kW}$ from $\mathrm{MG}_{2}$ is transferred to $\mathrm{MG}_{3}$ and $170 \mathrm{~kW}$ from $\mathrm{MG}_{2}$ is transferred to $\mathrm{MG}_{4}$. Although the load demand of $\mathrm{MG}_{3}$ is not fully supplied by the PV generation from $\mathrm{MG}_{1}$ and $\mathrm{MG}_{2}$, the $\mathrm{MG}_{2} \leftrightarrow \mathrm{MG}_{3}$ transmission cable limit restricts the power transfer to $\mathrm{MG}_{3}$ only $230 \mathrm{~kW}$ as shown in Table 4.1 . The algorithm also ensures that maximum power up to the cable limit is transferred from $\mathrm{MG}_{2}$ to $\mathrm{MG}_{3}$ as compared to power transfer from $\mathrm{MG}_{2}$ to $\mathrm{MG}_{4}$ as the transmission cable power losses is larger for $\mathrm{MG}_{2} \leftrightarrow \mathrm{MG}_{4}$ due to higher cable resistance. It can be clearly seen from Figure 4-3 that in 
grid-connected mode of operation, the remaining power of $408.93 \mathrm{~kW}$ and $702.76 \mathrm{~kW}$ required by the loads in $\mathrm{MG}_{3}$ and $\mathrm{MG}_{4}$ respectively are supplied from the electricity grid. The algorithm also compensates the transmission cable power losses for power transfers from $\mathrm{MG}_{1}$ to $\mathrm{MG}_{3}$ and from $\mathrm{MG}_{2}$ to $\mathrm{MG}_{3}$ by increasing the amount of power supplied from the grid to $\mathrm{MG}_{3}$ from $400 \mathrm{~kW}$ to $408.93 \mathrm{~kW}$. Similarly, the transmission loss for power transfer from $\mathrm{MG}_{2}$ to $\mathrm{MG}_{4}$ is compensated by increasing the amount of power supplied from the grid to $\mathrm{MG}_{4}$ from $700 \mathrm{~kW}$ to $702.76 \mathrm{~kW}$. It is assumed that the transmission cable power losses for power supplied from the electricity grid are not taken into account. The total cost for the energy trading within multi-microgrid of $1,861.69 \mathrm{~kW}$ (i.e., $350 \mathrm{~kW}+230 \mathrm{~kW}+170 \mathrm{~kW}+408.93 \mathrm{~kW}+702.6 \mathrm{~kW}$ ) for 30 minutes time interval is $\$ 188.06$ and thus the market clearing price $\lambda_{m m}$ calculated using (3.16) is $\$ 0.202 / \mathrm{kWh}$ which is cheaper than the grid electricity tariff of $\$ 0.2518 / \mathrm{kWh}$.

\subsection{Test Case 2: Islanded Mode of Operation with Insufficient Energy Generation from PV}

In this test case study, the excess PV generation of $\mathrm{MG}_{1}$ and $\mathrm{MG}_{2}$ and the load demand of $\mathrm{MG}_{3}$ and $\mathrm{MG}_{4}$ are similar to those used in Test Case 1 . The smart grid system is in the islanded mode of operation and thus the MT and DR are the major power sources that can be dispatched in the smart grid system if the PV energy generation is not sufficient to load demand. Without considering any constraints of the smart grid system, the total maximum available power from PVs and microturbines is $2,230 \mathrm{~kW}$ as shown in Table 4.2, which is sufficient to supply the total load demand of $1,850 \mathrm{~kW}$ for $\mathrm{MG}_{3}$ and $\mathrm{MG}_{4}$. However, due to the transmission cable power limit constraints shown in Table 4.1, the total power that can be transferred from other microgrids to $\mathrm{MG}_{3}$ is only $870 \mathrm{~kW}$ which is lower than the load demand of $980 \mathrm{~kW}$. This means that the total load demand of $\mathrm{MG}_{3}$ cannot be met completely by energy transfer from other microgrids. Therefore, $\mathrm{MG}_{3}$ has to operate its own MT to generate at least $110 \mathrm{~kW}$ even if the operation cost of its MT is high. Otherwise, DR of loads 
in $\mathrm{MG}_{3}$ will be invoked if the power generated by the MT is less than $110 \mathrm{~kW}$. As for $\mathrm{MG}_{4}$, based on the transmission cable power limit, the total power that can be transferred from other microgrids to $\mathrm{MG}_{4}$ is $970 \mathrm{~kW}$ which is higher than the load demand of $870 \mathrm{~kW}$. Therefore, $\mathrm{MG}_{4}$ may not need to operate its $\mathrm{MT}$ as the required power can be supplied from others microgrids.

The numerical results of the optimization algorithm for Test Case 2 are shown in Table 4.4 and are also graphically represented in Figure 4-2. From Table 4.4, it can be seen that the algorithm ensures that the excess $\mathrm{PV}$ generation from $\mathrm{MG}_{1}$ and $\mathrm{MG}_{2}$ is fully utilized where $232.2 \mathrm{~kW}$ from $\mathrm{MG}_{1}$ is transferred to $\mathrm{MG}_{3}, 117.8 \mathrm{~kW}$ from $\mathrm{MG}_{1}$ is transferred to $\mathrm{MG}_{4}$, $135 \mathrm{~kW}$ from $\mathrm{MG}_{2}$ is transferred to $\mathrm{MG}_{3}$ and $265 \mathrm{~kW}$ from $\mathrm{MG}_{2}$ is transferred to $\mathrm{MG}_{4}$. Based on the optimization, it can be seen from Figure 4-2 that the $\mathrm{MT}_{\mathrm{T}} \mathrm{MG}_{4}$ is set to generate $344.2 \mathrm{~kW}$ to meet its own load demand, and at the same time, $53.6 \mathrm{~kW}$ from $\mathrm{MG}_{4}$ is transferred to $\mathrm{MG}_{3}$. This is because the minimum energy generation cost subject to the transmission cable power limits and transmission loss constraints. With the proposed optimization algorithm, the $C_{T E T}$ is $\$ 335.23$. In comparison, if the $53.6 \mathrm{~kW}$ is generated by $\mathrm{MT}$ in $\mathrm{MG}_{3}$ instead of transferring from $\mathrm{MG}_{4}$. The $\mathrm{MT}$ in $\mathrm{MG}_{4}$ will set to generate $290.6 \mathrm{~kW}$ to meet its own load demand. In this case, the total fuel cost of MT energy generation is $\$ 511.54$ of which $\$ 318.44$ is the fuel cost $\lambda^{M T}$ calculated using (3.2) to generate $408.93 \mathrm{~kW}$ by $\mathrm{MT}$ in $\mathrm{MG}_{3}$ and $\$ 193.1$ is the fuel cost $\lambda^{M T}$ calculated using (3.2) to generate $290.6 \mathrm{~kW}$ by $\mathrm{MT}$ in $\mathrm{MG}_{4}$. This verifies that the proposed algorithm is able to achieve minimum $C_{T E T}$. The $\lambda_{m m}$ obtained is $\$ 0.36 / \mathrm{kWh}$ for energy trading of $1,875.33 \mathrm{~kW}$ for 30 minutes time interval. The $\lambda_{m m}$ in this test case is higher than $\$ 0.202 / \mathrm{kWh}$ of Test Case 1 because in Test Case 1 the load demand is supplied by cheaper electricity from the grid. 
Table 4.4 Numerical results for test case 2

\begin{tabular}{|c|c|c|c|c|}
\hline Source & $\begin{array}{c}\mathrm{PV} \\
(\mathrm{kW})\end{array}$ & $\begin{array}{c}\mathrm{DR} \\
(\mathrm{kW})\end{array}$ & $\begin{array}{c}\mathrm{MT} \\
(\mathrm{kW})\end{array}$ & $\begin{array}{c}\mathrm{P}_{\text {loss }} \\
(\mathrm{kW})\end{array}$ \\
\hline $\mathrm{MG}_{1} \rightarrow \mathrm{MG}_{3}$ & 232.2 & - & 117.8 & 6.24 \\
\hline $\mathrm{MG}_{2} \rightarrow \mathrm{MG}_{3}$ & 135 & - & 95 & 2.69 \\
\hline $\mathrm{MG}_{3} \rightarrow \mathrm{MG}_{3}$ & - & - & 355.53 & - \\
\hline $\mathrm{MG}_{4} \rightarrow \mathrm{MG}_{3}$ & - & - & 53.6 & 0.2 \\
\hline $\mathrm{MG}_{1} \rightarrow \mathrm{MG}_{4}$ & 117.8 & - & 117.8 & 3.82 \\
\hline $\mathrm{MG}_{2} \rightarrow \mathrm{MG}_{4}$ & 265 & - & 95 & 12.38 \\
\hline $\mathrm{MG}_{3} \rightarrow \mathrm{MG}_{4}$ & - & - & - & - \\
\hline $\mathrm{MG}_{4} \rightarrow \mathrm{MG}_{4}$ & - & - & 290.6 & - \\
\hline
\end{tabular}

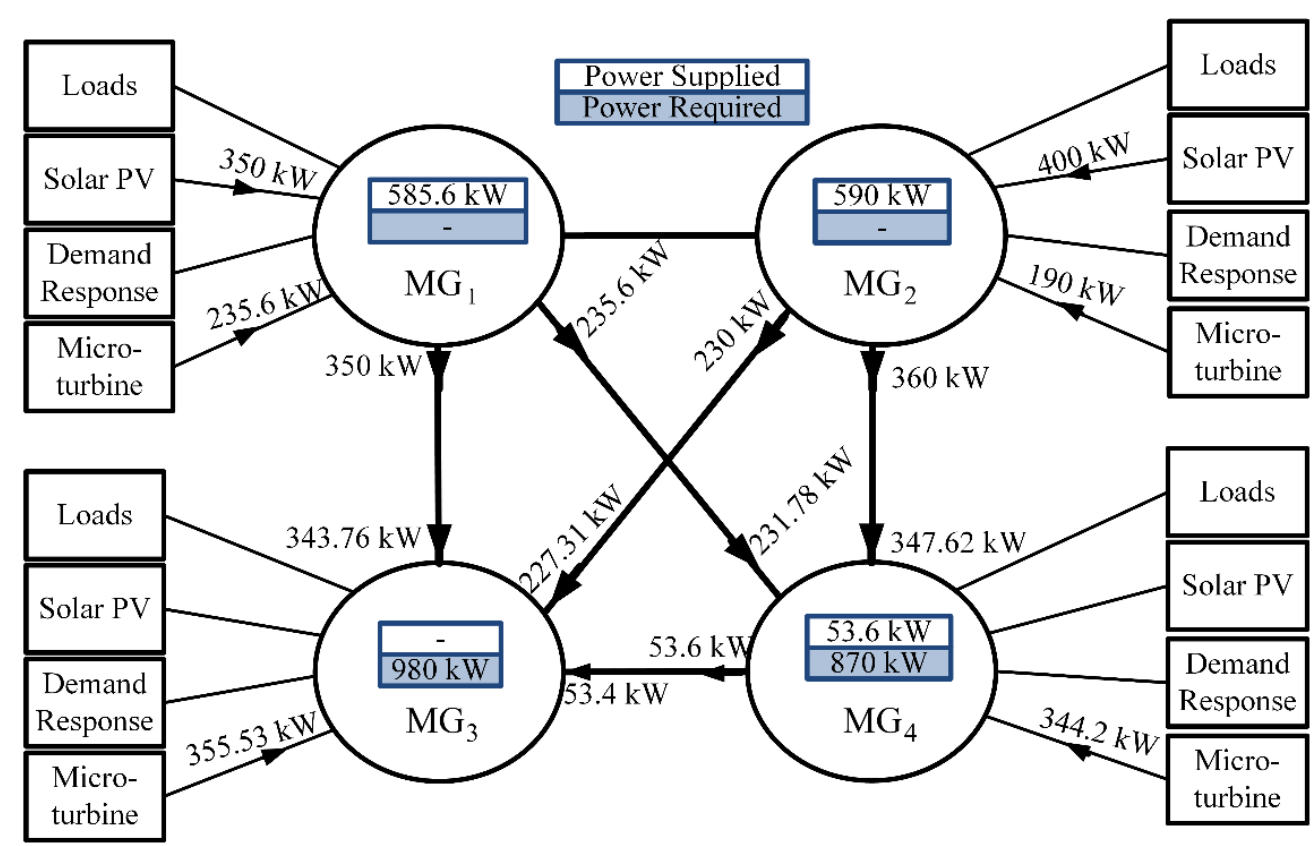

Figure 4-2: Test Case 2: Power supplied to microgrids with load demand. 


\subsection{Test Case 3: Islanded Mode of Operation with Insufficient Energy Generation from PV and MT}

In this test case study, the load demands of $\mathrm{MG}_{3}$ and $\mathrm{MG}_{4}$ are increased to $1,050 \mathrm{~kW}$ and $1,200 \mathrm{~kW}$, respectively. The excess PV generation of $\mathrm{MG}_{1}$ and $\mathrm{MG}_{2}$, and the $\mathrm{MT}$ generation capacities are similar to those used in Test Cases 1 and 2. Since the total amount of PV generation of $750 \mathrm{~kW}$ from $\mathrm{MG}_{1}$ and $\mathrm{MG}_{2}$ is insufficient to supply the total load demand requirement of $2,250 \mathrm{~kW}$ for $\mathrm{MG}_{3}$ and $\mathrm{MG}_{4}$, the power shortage of $1,500 \mathrm{~kW}$ must be supplied from other sources in the smart grid system in the islanded mode of operation. Without considering any constraints of the smart grid system, it can be observed from Table 4.2 that the maximum available power from MT in smart grid system is only $1,480 \mathrm{~kW}$ which is insufficient to supply the power shortage of $1,500 \mathrm{~kW}$. Therefore, the execution of DR is required in this test case. The optimization algorithm based on the cost of demand response and maximum shedding capacities in all four microgrids can invoke DR to shed a portion of load demand in the microgrids in order to reduce the total load demand requirement. The maximum shedding capacities that can be obtained from demand response and their associated cost for the four microgrids are given in Table 4.2.

The numerical results of the optimization algorithm for Test Case 3 are shown in Table 4.5 and are also graphically represented in Figure 4-3. From Table 4.5, it can be analyzed that the excess $\mathrm{PV}$ generation from $\mathrm{MG}_{1}$ and $\mathrm{MG}_{2}$ is fully utilized where $200 \mathrm{~kW}$ from $\mathrm{MG}_{1}$ is transferred to $\mathrm{MG}_{3}, 150 \mathrm{~kW}$ from $\mathrm{MG}_{1}$ is transferred to $\mathrm{MG}_{4}, 135 \mathrm{~kW}$ from $\mathrm{MG}_{2}$ is transferred to $\mathrm{MG}_{3}$ and $265 \mathrm{~kW}$ from $\mathrm{MG}_{2}$ is transferred to $\mathrm{MG}_{4}$. The power shortage of $1,500 \mathrm{~kW}$ is supplied by operating the MT in all four microgrids. It can also be observed that the $\mathrm{MT}$ in $\mathrm{MG}_{1}, \mathrm{MG}_{3}$ and $\mathrm{MG}_{4}$ are operated to maximum output power capacities to supply either to their own load demands or to $\mathrm{MG}_{3}$ and $\mathrm{MG}_{4}$. However, although the maximum output power of the $\mathrm{MT}$ in $\mathrm{MG}_{2}$ is $340 \mathrm{~kW}$, only a total of $190 \mathrm{~kW}$ is supplied to $\mathrm{MG}_{3}$ and $\mathrm{MG}_{4}$ as the maximum transmission cable reach power limits for $\mathrm{MG}_{2} \leftrightarrow \mathrm{MG}_{3}$ and $\mathrm{MG}_{2} \leftrightarrow \mathrm{MG}_{4}$. In addition, $8.93 \mathrm{~kW}$ and $18.58 \mathrm{~kW}$ of transmission cable power losses must also be compensated by the $\mathrm{DR}$ in $\mathrm{MG}_{3}$ and $\mathrm{MG}_{4}$, respectively. Thus, the optimal DR 
amount of $68.93 \mathrm{~kW}$ and $128.58 \mathrm{~kW}$ are obtained for $\mathrm{MG}_{3}$ and $\mathrm{MG}_{4}$, respectively. It should be noted that DR is not constrained by the transmission cable power limit and does not account for transmission cable power losses as it does not involve actual power transfer. The total cost for the energy trading of $2,277.51 \mathrm{~kW}$ (i.e., $=350 \mathrm{~kW}+300 \mathrm{~kW}+68.93 \mathrm{~kW}$ $+410 \mathrm{~kW}+400 \mathrm{~kW}+190 \mathrm{~kW}+128.58 \mathrm{~kW}+430 \mathrm{~kW}$ ) for 30 minutes time interval is $\$ 625.22$ and thus the market clearing price $\lambda_{m m}$ calculated using (3.16) is $\$ 0.56 / \mathrm{kWh}$. The $\lambda_{m m}$ is higher than $\$ 0.202 / \mathrm{kWh}$ of Test Cases 1 and $\$ 0.36 / \mathrm{kWh}$ of Test Cases 2 as demand response which is a more expensive source of power is executed to achieve supply-demand balance in the smart grid system.

Table 4.5 Numerical results for test case 3

\begin{tabular}{|c|c|c|c|c|}
\hline & $\begin{array}{c}\text { SV } \\
(\mathrm{kW})\end{array}$ & $\begin{array}{c}\mathrm{DR} \\
(\mathrm{kW})\end{array}$ & $\begin{array}{c}\mathrm{MT} \\
(\mathrm{kW})\end{array}$ & $\begin{array}{c}\mathrm{P}_{\text {loss }} \\
(\mathrm{kW})\end{array}$ \\
\hline $\mathrm{MG}_{1} \rightarrow \mathrm{MG}_{3}$ & 200 & - & 150 & 6.24 \\
\hline $\mathrm{MG}_{2} \rightarrow \mathrm{MG}_{3}$ & 135 & - & 95 & 2.69 \\
\hline $\mathrm{MG}_{3} \rightarrow \mathrm{MG}_{3}$ & - & 68.93 & 410 & - \\
\hline $\mathrm{MG}_{4} \rightarrow \mathrm{MG}_{3}$ & - & - & - & - \\
\hline $\mathrm{MG}_{1} \rightarrow \mathrm{MG}_{4}$ & 150 & - & 150 & 6.2 \\
\hline $\mathrm{MG}_{2} \rightarrow \mathrm{MG}_{4}$ & 265 & - & 95 & 12.38 \\
\hline $\mathrm{MG}_{3} \rightarrow \mathrm{MG}_{4}$ & - & - & - & - \\
\hline $\mathrm{MG}_{4} \rightarrow \mathrm{MG}_{4}$ & - & 128.58 & 430 & - \\
\hline
\end{tabular}




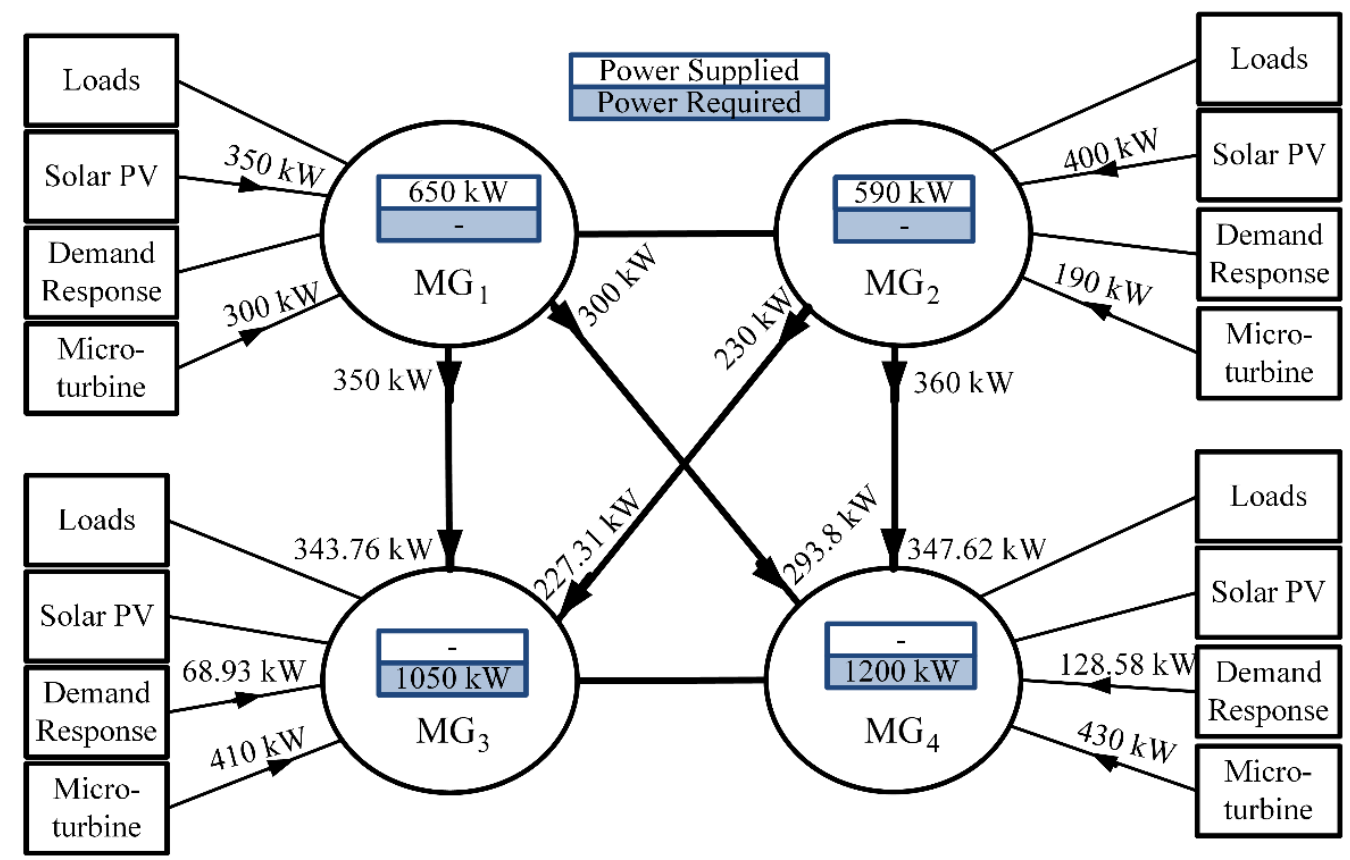

Figure 4-3: Test Case 3: Power supplied to microgrids with load demand.

\subsection{Summary}

The proposed EMS concept was demonstrated through different test case scenarios and the results obtained were discussed in this section. The results showed that the proposed MILP optimization algorithm for EMS in the multi-microgrid architecture can ensure power balance within the smart grid system with minimal energy trading cost under different modes of operation. Through the test case studies conducted in this section, it was observed that the proposed optimization algorithm has the capability to handle a multi-constraint complex system to ensure that the smart grid system operates in an economic manner. Overall, the proposed hierarchical architecture design for multi-microgrid and the developed optimization algorithm for the EMS ensure that the smart grid system operates in a coordinated and economic manner. 


\section{Chapter 5}

\section{Business Case Model of the EMS Integration for Smart Grid's Multi-Agent System}

\subsection{Introduction}

In order to achieve energy trading between different microgrids in a smart grid system, the infrastructures such as AMI and DR for EMS are required. All these new add-on infrastructures will be an additional cost in developing a smart grid system. A business model will help the utility or investor to have a sensitivity study on the investment of smart grid system. However, many of today's utility business models are based on the utility earning a negotiated return on prudent capital investments. In general, the existing utility business model does not provide economic rewards for cutting-edge technologies. In addition, the value of smart grid technologies has been difficult to quantify in a simple costbenefit analysis due to the multi-tiered benefits they provide to the utility, consumer, and society. This chapter will discuss business models which include the cost-benefit analysis of advanced metering infrastructure, demand side management, DG management, demand response management and energy efficiency system, especially in the areas of investment costs, cost savings and payback years for the integration of smart grid in Singapore.

\subsection{Cost-Benefit Analysis of Advanced Metering Infrastructure}

The ownership of the AMI network will incur different costs to the smart grid operator. In the event when the smart grid operator owns and operates the AMI network as opposed to paying an outside vendor to own and operate the AMI network, the smart grid operator will need to perform a proper cost assessment for the deployment of the AMI network. The detailed cost assessment is conducted to determine the total life cycle cost components associated with AMI deployment in Singapore including the operation and maintenance 
(O\&M) costs. The major cost components of the AMI deployment are breakdown as follows:

\section{- Smart Meter and Deployment Cost}

We assume the smart grid operator is to incur the cost of the smart meter. Smart meter costs include the costs for the total number of single-phase and three-phase smart meters having embedded two-way communication modules. In addition, annual growth rate $\lambda$ is also considered over the deployment years since it is impossible to deploy all the smart meters within one year. Growth rate is based on the percentage of the initial number of smart meters that will be deployed at the start of the project. Another cost driver that is considered in these cost components is the accelerated depreciation for existing electromechanical meters and automated meter reading (AMR) meters. This is because all existing meters that will be replaced during the AMI deployment period will still have a depreciable life remaining at the point they are replaced. Double declining balance depreciation method is used to obtain the depreciation value $D V$ of existing meters. The cost for the smart meters and their installation is given by

$$
C_{\text {meter }}=\left[1+D_{Y} \cdot \lambda_{1 \Phi}\right] N_{i, 1 \Phi} \cdot\left(C_{i, 1 \Phi}+I_{i, 1 \Phi}\right)+\left[1+D_{Y} \cdot \lambda_{3 \Phi}\right] N_{i, 3 \Phi} \cdot\left(C_{3 \Phi}+I_{i, 3 \Phi}\right)+D V
$$

where

$$
D V=2 \cdot N_{e, 1 \Phi}\left[\left(C_{e, 1 \Phi}-S V_{e, 1 \Phi}\right) / B Y_{e, 1 \Phi}\right]+2 \cdot N_{e, 3 \Phi}\left[\left(C_{e, 3 \Phi}-S V_{e, 3 \Phi}\right) / B Y_{e, 3 \Phi}\right]
$$

$D_{Y}$ is the number of deployment years of the AMI project, $\lambda_{1 \Phi}$ and $\lambda_{3 \Phi}$ are the annual growth rate in percentage of single-phase and three-phase meters respectively, $N_{i, 1 \Phi}$ and $N_{i, 3 \Phi}$ are the initial number of single-phase and three-phase meters that will be deployed at the start of the AMI project respectively, $C_{i, 1 \Phi}$ and $C_{i, 3 \Phi}$ are the cost in dollars of one new singlephase and one new three-phase meters respectively, $I_{i, 1 \Phi}$ and $I_{i, 3 \Phi}$ are the installation cost in dollars of one single-phase and one three-phase meters respectively, $N_{e, 1 \Phi}$ and $N_{e, 3 \Phi}$ are the existing number of single-phase and three-phase meters that would be replaced by a smart meter respectively, $C_{e, 1 \Phi}$ and $C_{e, 3 \Phi}$ are the cost in dollars of one existing single-phase and one existing three-phase meters respectively, $S V_{e, 1 \Phi}$ and $S V_{e, 3 \Phi}$ are the salvage value in 
dollars of one existing single-phase and one existing three-phase meters respectively, and $B Y_{e, 1 \Phi}$ and $B Y_{e, 3 \Phi}$ are the balance number of useable years of one existing single-phase and one existing three-phase meters respectively.

Installation of the smart meters is a complex activity involving pre-installation preparations and field deployment. During pre-installation, facilities must be prepared for AMI meter installation process. This involves setting up facilities as logistical hubs for meter deployment and each smart meter must be tested for performance and accuracy before deployment. Installation schedule based on route plan must also be developed for meter deployment. Training of manpower is another pre-installation preparation that needs to be carried out. In addition, the communication network is commissioned first to provide immediate visibility to the smart meters that will be installed. Network communication preparation includes field survey, installation and testing of communication equipment. During field deployment, the smart meters are actually installed at the consumer premises while existing meters are taken out of service. Tests of meter communication and data accuracy are performed as a part of commissioning. It must be noted that during field deployment period, the smart grid operator will incur outage losses due to disconnection of consumer electricity supply. Therefore, the total cost for the smart meter deployment for an AMI project is given by

$$
C_{M D}=C_{m e t e r}+C_{P I P}+C_{C N P}+\left[1+D_{Y} \cdot \lambda_{1 \Phi}\right] N_{i, 1 \Phi} \cdot L_{O, 1 \Phi}+\left[1+D_{Y} \cdot \lambda_{3 \Phi}\right] N_{i, 3 \Phi} \cdot L_{O, 3 \Phi}
$$

where $C_{P I P}$ is the pre-installation preparation cost, $C_{C N P}$ is the communication network preparation cost and $L_{O, 1 \Phi}$ and $L_{O, 3 \Phi}$ are the outage losses in dollars of one existing singlephase and one existing three-phase meters respectively.

\section{- Communication Infrastructure and Implementation Cost}

The AMI communication infrastructure implementation involves the physical roll-out of the communication network hardware in the AMI coverage area and within the smart grid 
operator facilities. A typical smart grid communication infrastructure for Singapore is shown in Figure 5-1. The communication network hardware cost includes costs of data concentrator units, wide area network (WAN) hardware and backend communication equipment.

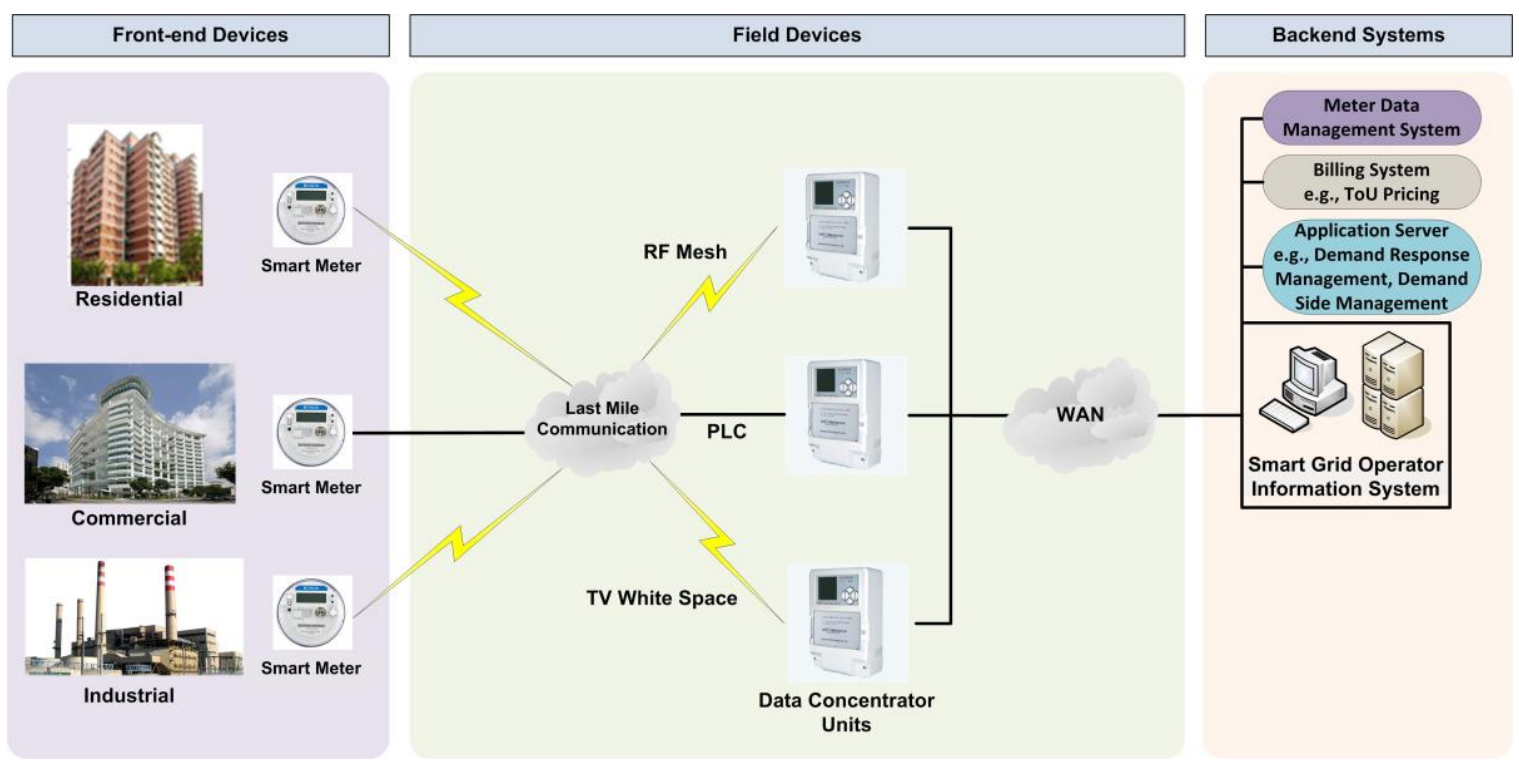

Figure 5-1: AMI communication infrastructure for Singapore.

In addition, communication network licensing cost must also be considered if wireless communication is employed for the last mile and/or backhaul communication. Therefore, the cost for the communication infrastructure and implementation can be expressed as

$$
C_{\text {comms }}=N_{D C U} \cdot\left(C_{D C U}+I_{D C U}\right)+N_{W A N} \cdot\left(C_{W A N}+I_{W A N}\right)+N_{B E} \cdot\left(C_{B E}+I_{B E}\right)
$$

where $N_{D C U}, N_{W A N}$ and $N_{B E}$ are the number of data concentrator units, wide area network (WAN) hardware and backend communication equipment required for the AMI project respectively, $C_{D C U}, C_{W A N}$ and $C_{B E}$ are the cost in dollars of one data concentrator unit, one WAN hardware and one backend communication equipment respectively, and $I_{D C U}, I_{W A N}$ and $I_{B E}$ are the installation cost in dollars of one data concentrator unit, one WAN hardware and one backend communication equipment respectively. 


\section{- Information Technology Systems and Integration}

The key component of the Information Technology (IT) system for AMI is the backend system which communicates with the AMI communication network to collect smart meter data, send control commands to the smart meter and perform meter data analytics. The backend system consists of network operation hardware such as servers, routers and data storage. Meter Data Management System (MDMS) software is used to validated the meter data to ensure data quality. MDMS also performs estimations for missing/inaccurate data. Usually meter data will need to be shared by several systems; therefore, an integration platform is required to allow sharing of the information between various enterprise systems such as billing, consumer service and consumer analytics. The cost for the security of the AMI network, including planning and implementation of the security architecture to protect consumer and operational data, must also be considered. In addition, manpower is needed to perform software application design, implementation and integration of the IT system as well as system maintenance. The total cost for the IT system and integration $C_{I T}$ can be expressed as

$$
C_{I T}=C_{\text {BEhardware }}+C_{M D M S}
$$

where $C_{B E h a r d w a r e}$ is the total hardware cost for the backend system and $C_{M D M S}$ is the cost of the MDMS software.

\section{- Project Management Cost}

AMI deployment is a long-term project which requires substantial amount of resources for program delivery activities. Project management is the process and activity of planning, organizing, motivating, and controlling resources, procedures and protocols to achieve specific milestones in the deployment of AMI over the estimated deployment years. The project management team will be responsible for many activities including project scheduling, manpower recruitment, project communication and reporting, vendor/contract 
management, etc. Therefore, the project management cost $C_{P M}$ should be included in the overall AMI project cost. The project management cost is given by

$$
C_{P M}=P M_{\cos t} \cdot D_{Y}
$$

where $P M_{\text {cost }}$ is the annual cost for project management and $D_{Y}$ is the number of deployment years.

\section{- AMI Operation and Maintenance Cost}

This cost category represents the costs for supporting AMI operational activities such as metering and communication throughout the project life cycle. AMI metering operation including performing routine maintenance to meters, diagnosing problems and repair meters that fail, and attending to service calls after AMI meters are installed. Communication operation costs include backhaul communication data charges, costs for maintaining the AMI communication networks, rent/charges for using facilities and manpower cost for network operation engineers, field/telecom operation technicians and supervisors. The annual O\&M cost $C_{O M}$ is formulated as

$$
C_{O M}=\left(C_{M O}+C_{C O}+S L_{\text {fees }}+C L_{\text {fees }}+M_{I T}\right) \cdot P_{Y}
$$

where $C_{M O}$ is the annual metering operation cost, $C_{C O}$ is the annual communication operation cost, $S L_{f e e s}$ is the total annual software cost, $C L_{f e e s}$ is the annual communication network licensing fees, $M_{I T}$ is the annual IT system operating manpower cost and $P_{Y}$ is the project life cycle in years.

Thus, the total cost of the AMI program is obtained through summation of the major cost components described above. The total AMI cost over the project life cycle $C_{A M I}$ is expressed as 


$$
C_{A M I}=C_{M D}+C_{\text {comms }}+C_{I T}+C_{P M}+C_{O M}
$$

The author also conducted a thorough assessment of all direct operational benefits associated with the AMI program in Singapore. The following are the major quantifiable benefits expected from the AMI implementation:

\section{- Meter Reading Cost Reduction}

Traditionally, meter readings are conducted through physical site visits to the consumer premises which now can be eliminated as a result of automated meter reading through the AMI system. Therefore, the major cost savings that can be derived from AMI implementation is through the reduction in manpower costs for manual meter reading as well as the associated transportation costs. Transportation related cost savings include from fuel costs, vehicle insurance, and vehicle maintenance. In the case when part of the meter reading is conducted through existing AMR system, then the associated cost reduction in manpower cost, IT cost and O\&M cost associated with the IT system should be included in the cost savings calculation. The annual saving in meter reading cost $S_{M R}$ is given by

$$
S_{M R}=\left(N_{M R} \cdot A S_{M R}\right)+T_{M R}+C_{A M R}
$$

where $N_{M R}$ is the number of meter readers, $A S_{M R}$ is the average annual salary of meter readers, $T_{M R}$ is the annual transportation cost for manual meter reading and $C_{A M R}$ is the annual AMR meter reading cost.

\section{- Reduction of Unaccounted for Energy}

Unaccounted for energy can be caused by meter tampering, energy theft, meter inaccuracy, and failed meters which may result in significant revenue loss for the smart grid operator. Revenue losses related to unmetered energy can be reduced through the use of smart meters and sophisticated meter data management systems. In particular, AMI enables early detection of meter tampering and energy theft through the use of analytics software. Also, 
AMI helps smart grid operator to quickly identify failed meter that cannot measure electricity and take steps to repair or replace the failed meter, thereby reducing potential revenue losses. The annual cost saving in reduction of unaccounted for energy $S_{U E}$ can be expressed as

$$
S_{U E}=T_{U E}+F_{U E}
$$

where $T_{U E}$ is the annual theft/tamper-associated revenue loss and $F_{U E}$ is the annual revenue loss for unaccounted energy due to failed meter.

\section{- Reduction in Field and Meter Services}

AMI allows the smart grid operator to perform several functions remotely and thus reduce the need for field visits to the customer premises. This will provide significant cost savings through the reduction in the number of manpower and vehicles required for field and meter services. Typical field and meter services that can be reduced with the availability of AMI include:

$>$ Manual disconnect/reconnect of meters for new and cancelled accounts or for consumers who do not pay promptly;

$>$ Manual meter reading for change of tenants, high bill inquiries, and other instances when meter reading is required off the normal monthly reading cycle;

$>$ Redundant outage field trips that are caused by consumer electrical equipment or when outage is restored before arrival.

The annual cost saving in reduction of field and meter services $S_{F M S}$ can be expressed as

$$
S_{F M S}=M_{M C}+M_{S R}+M_{O R}+T_{F M S}
$$

where $M_{M C}$ is the annual cost for manual disconnect/reconnect of meters, $M_{S R}$ is the annual cost for manual off-cycle/special meter reads, $M_{O R}$ is the annual cost for redundant outage field trips and $T_{F M S}$ is the annual transportation cost for carrying out field and meter services. 
Thus, the annual cost saving from the AMI program is obtained through summation of the major quantifiable benefits described above. The annual AMI cost saving $S_{A M I}$ is expressed as

$$
S_{A M I}=S_{M R}+S_{U E}+S_{F M S}
$$

Using the cost data obtained from the AMI implementation of 320 smart meters at NTU campus, the author scaled up the cost to perform the cost benefit analysis for AMI with 32,000 smart meters. The cost of each component of the AMI is tabulated in Table 5.1.

Table 5.1: AMI cost components

\begin{tabular}{|l|l|}
\hline \multicolumn{1}{|c|}{ AMI Component } & \multicolumn{1}{c|}{ Cost } \\
\hline Single-phase smart meters including installation & $\mathrm{S} \$ 400$ \\
\hline Three-phase smart meters including installation & $\mathrm{S} \$ 900$ \\
\hline Existing single-phase meters & $\mathrm{S} \$ 100$ \\
\hline Existing three-phase meters & $\mathrm{S} \$ 200$ \\
\hline Salvage value of existing single-phase and three-phase meters & $\mathrm{S} \$ 0$ \\
\hline Outage losses of one existing single-phase meter during installation (2kWh) & $\mathrm{S} \$ 0.51$ \\
\hline Outage losses of one existing three-phase meter during installation (5kWh) & $\mathrm{S} \$ 1.29$ \\
\hline PLC or RF communication module & $\mathrm{S} \$ 211.50$ \\
\hline PLC or RF data concentrator unit (DCU) including installation & $\mathrm{S} \$ 1,364$ \\
\hline Wide area network (WAN) access point and installation & $\mathrm{S} \$ 500$ \\
\hline Backend communication equipment and installation & $\mathrm{S} \$ 10,000$ \\
\hline Backend IT system for 32,000 smart meter data collection & $\mathrm{S} \$ 500,000$ \\
\hline MDMS software and communication licensing fees & $\mathrm{S} \$ 40 / m e t e r$ \\
\hline Project management for 3 years & $\mathrm{S} \$ 500,000$ \\
\hline Annual software and communication network licensing fees & $\mathrm{S} \$ 128,000$ \\
\hline Annual metering and communication operation cost & $\mathrm{S} \$ 62,920$ \\
\hline Annual IT system operating manpower cost & $\mathrm{S} \$ 40,000$ \\
\hline
\end{tabular}

Based on $D_{Y}=3$ years, $\lambda_{1 \Phi}=1 \%, \lambda_{3 \Phi}=1 \%, N_{i, 1 \Phi}=25,000, N_{i, 3 \Phi}=7,000, B Y_{e, 1 \Phi}=10$ years and $B Y_{e, 3 \Phi}=10$ years, the total capital cost estimated for the AMI project is $\mathrm{S} \$ 25,850,267$ while the annual O\&M cost is estimated at $\mathbf{S} \$ 230,920$. In this case scenario, the following are considered in the base case:

- 10 meter readers are hired at an annual salary of $S \$ 40,000$ each to perform manual meter reading of 32,000 meters

- Annual transportation cost for manual meter reading is $\mathbf{S} \$ 250,000$ 
- Annual revenue losses due to theft/tamper-associated and failed meter are estimated at $1 \%$ of the total revenue [42]

- Annual cost for manual disconnect/reconnect of meters, manual off-cycle/special meter reads and redundant outage field trips is estimated at $3 \%$ of the total revenue [42]

○ Annual transportation cost for carrying out field and meter services is estimated at S\$100,000

The total annual saving from the AMI project is estimated at $\mathbf{S} \$ 1,861,956$. The result of the financial analysis obtained from the smart grid cost benefit analysis system is shown in Figure 5-6. A simple payback period of 15.85 years is calculated for the AMI project. It can be seen that the AMI project will take about 19 years to achieve positive cumulative cash flow based on a $30 \%$ debt ratio at an interest rate of $5.5 \%$ which shows that the project is viable. Furthermore, the benefit to cost $(\mathrm{B}-\mathrm{C})$ ratio is greater than 1 which indicates that the benefit from the project outperforms the cost involved. This also means that over the project life time of 20 years, the cost savings from the AMI project will be able to pay back the investment and other annual costs.

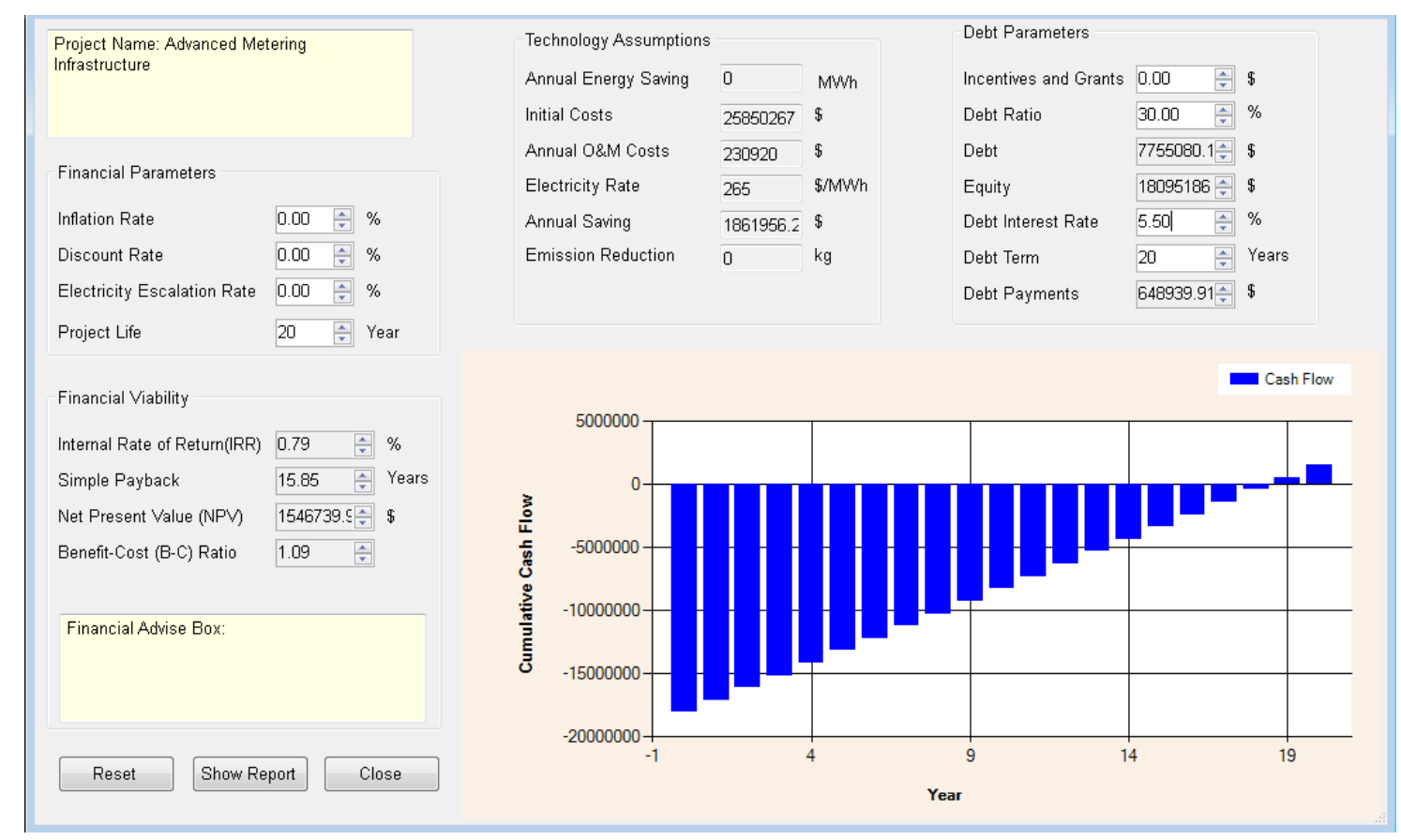

Figure 5-2: AMI project financial analysis. 


\subsection{Cost-Benefit Analysis of Demand Response Management}

DR management aims to manage and change the electricity consumption patterns of consumers during system constraints and peak demands. DR is achieved through the implementation of control algorithms such as EMS that curtail loads in response to market price conditions, demand limits, or a request by the utility. In these control algorithms, interruptible loads such as lights, water heaters and air conditioning units are shed according to the consumers' priority-based load shedding requirements during peak demand periods. This will help level the load on the distribution grid and therefore raise the overall efficiency of the power grid. DR management can help keep the grid in balance when energy supplies get tight, or when more renewable energy sources such as PVs and wind turbines are being integrated into the power distribution grid.

\section{Demand Response Program Costs and Benefits}

Different DR program costs and benefits must be considered when evaluating the costeffectiveness of the DR program. A list of DR program costs and benefits for the program administrator and the participants are provided in Tables 5.2 and 5.3 respectively.

Table 5.2: Demand response program costs

\begin{tabular}{|l|c|c|c|c|}
\hline & \multicolumn{4}{|c|}{ Costs } \\
\hline $\begin{array}{l}\text { Smart grid } \\
\text { operator }\end{array}$ & $\begin{array}{c}\text { Program } \\
\text { administrator } \\
\text { expenses }\end{array}$ & $\begin{array}{c}\text { Program } \\
\text { administrator } \\
\text { capital costs }\end{array}$ & $\begin{array}{c}\text { Financial } \\
\text { incentive to } \\
\text { participants }\end{array}$ & $\begin{array}{c}\text { DR measure cost: } \\
\text { program } \\
\text { administrator } \\
\text { contribution }\end{array}$ \\
\hline Participant & DR measure & Participant & Participant value & \\
& cost: participant \\
contribution & transaction & costs & & ---- \\
\hline
\end{tabular}


Table 5.3: Demand response program benefits

\begin{tabular}{|l|c|c|c|c|c|}
\hline & \multicolumn{5}{|c|}{ Benefits } \\
\hline opmart grid & $\begin{array}{c}\text { Avoided } \\
\text { capacity } \\
\text { costs }\end{array}$ & $\begin{array}{c}\text { Avoided } \\
\text { energy } \\
\text { costs }\end{array}$ & $\begin{array}{c}\text { Avoided } \\
\text { transmission } \\
\text { and distribution } \\
\text { costs }\end{array}$ & $\begin{array}{c}\text { Avoided } \\
\text { ancillary } \\
\text { service costs }\end{array}$ & $\begin{array}{c}\text { Revenues from } \\
\text { wholesale DR } \\
\text { programs }\end{array}$ \\
\hline Participant & $\begin{array}{c}\text { Participant } \\
\text { bill savings }\end{array}$ & $\begin{array}{c}\text { Financial } \\
\text { incentive to } \\
\text { participants }\end{array}$ & Tax credits & - & - \\
\hline
\end{tabular}

\subsubsection{Energy Market Authority Model}

According to [43], when licensed load providers are allowed to provide load curtailments in a particular period, the Market Clearing Engine (MCE) will be run twice, once with load curtailment and once without load curtailment. The Uniform Singapore Energy Price (USEP) generated in the former case will be the market clearing price paid by market participants for the half-hour period while the price generated in the latter case serves as a counterfactual USEP as though the DR programme was not in place during the half-hour period. The difference in these two prices, which is the Implicit Demand Response Rebate (IDRP) is given by

$$
U S E P_{w / o}-U S E P_{w}=I D R P
$$

where $U S E P_{w / o}$ is the counterfactual USEP generated without the load curtailed and $U S E P_{w}$ is the actual USEP with the load curtailed. The IDRP is then used to calculate the payback period for the implementation of DR at the consumer side and the utility side.

\section{- Payback Period for Implementation of Demand Response}

The number of payback years for the implementation of DR at the consumer side is given as follows: 
Simple Payback Period $($ years $)=\frac{\left(I D R P \times E_{c}\right)-C_{o m}}{C_{i}}$

where $E_{c}$ is the total energy committed by the participant for DR per year, $C_{o m}$ is the incremental overheads and maintenance costs, and $C_{i}$ is the incremental initial cost.

The number of payback years for the implementation of DR at the utility side is given as follows:

$$
\text { Simple Payback Period (years) }=\frac{\frac{2}{3} \times\left[\operatorname{IDRP} \times\left(E_{t}-E_{r c}\right)\right] \times h r \times 365-C_{o m}}{C_{i}}
$$

where $E_{i}$ is the total energy demand, $E_{r c}$ is the energy demand associated with regulatory contracts, and $h r$ is the number of operating hours.

\subsubsection{Cost-Benefit Analysis of Implementing Demand Response in Smart Grids}

In this section, the payback period required for implementing DR in a smart grid for the both the smart grid operator and the participant is calculated using a test scenario to determine its financial viability. In this test scenario, the building load demand in a smart grid is assumed to have a peak demand of $24 \mathrm{MW}$ and $30 \mathrm{MW}$ at $10.00 \mathrm{am}$ and $2.00 \mathrm{pm}$ respectively. In order to achieve $20 \%$ peak shaving at $10.00 \mathrm{am}(4.8 \mathrm{MW})$ and $2.00 \mathrm{pm}$ $(6 \mathrm{MW})$, the smart grid operator initiated DR for 10.00am - 10.30am and 2.00pm $-2.30 \mathrm{pm}$.

Cost of energy consumption before DR:

From [40], the electricity tariff for high tension (large consumers) $=\mathrm{S} \$ 0.2345 / \mathrm{kWh}$

Cost at peak periods $=$ Total peak demand $(\mathrm{kW}) \times$ No. of hrs $x$ Electricity tariff $(\$ / \mathrm{kWh})$

$$
=(24+30) \times 1000 \times 0.5 \times 0.2345=\mathrm{S} \$ 6,331.50
$$

Cost of energy consumption after DR: 
Cost at new peak $=[(24-4.8)+(30-6)] \times 1000 \times 0.5 \times 0.2345=\mathrm{S} \$ 5,065.20$

\section{Cost difference:}

Cost difference $=$ cost before DR - cost after DR $=\mathrm{S} \$ 6,331.50-\mathrm{S} \$ 5,065.20=\mathrm{S} \$ 1,266.30$

Assuming that the cost difference is divided into $33 \%$ as incentives and $67 \%$ as revenue savings incurred from DR $=67 \%$ x $\mathrm{S} \$ 1266.30=\mathrm{S} \$ 848.42$

Assuming that DR is initiated 2 times per day for a period of one year and the savings incurred is the same throughout the year, the annual cost savings for the smart grid can be calculated as follows:

Savings per year for smart grid $=\mathrm{S} \$ 848.42 \times 365$ days $=\mathrm{S} \$ 30,9673.30$

The payback period can be calculated using

$$
T=\frac{I}{R}
$$

where $T$ is the payback period, $I$ is the initial investment and $R$ is the revenue per annum.

The investment cost for the smart grid operator and the participants will vary according to the size of the building and amount of controls required. Hence, a large building with a sophisticated control requirement will incur more investment cost. In order to determine the payback period required by the smart grid operator and the participant for investing in DR, an estimation of the implementation costs is made as shown in Tables 11 and 12 respectively.

Table 5.4: Investment cost for smart grid operator

\begin{tabular}{|l|l|}
\hline Communications Network Systems \& IT & $\mathrm{S} \$ 1.5$ million \\
\hline Manpower & $\mathrm{S} \$ 0.5$ million \\
\hline Estimated Total Cost & $\mathrm{S} \$ 2$ million \\
\hline
\end{tabular}


Table 5.5: Investment cost for participant

\begin{tabular}{|l|l|}
\hline Relays & $\mathrm{S} \$ 63.5 /$ relay x 50 \\
\hline Control Devices (Timers) & $\mathrm{S} \$ 25 /$ timer x 50 \\
\hline Smart Meters & $\mathrm{S} \$ 105 /$ meter x 50 \\
\hline Manpower & $\mathrm{S} \$ 100 /$ person x 2 \\
\hline Estimated Total Cost & $\mathrm{S} \$ 9,875$ \\
\hline
\end{tabular}

From (5.14), it can be calculated that the smart grid is able to recover its investment cost after 6.46 years.

As for the participant, it is assumed that one of the participants has been scheduled to curtail $340 \mathrm{~kW}$ of load at the offered bid price of $\mathrm{S} \$ 0.21 / \mathrm{kWh}$ for a duration of half an hour.

Incentive $=$ Load distribution $(\mathrm{kW}) \times$ No. of hrs $\times$ Price bid $(\mathrm{S} \$ / \mathrm{kWh})=340 \times 0.5 \times \mathrm{S} \$ 0.21=$ $\mathrm{S} \$ 35.70$

Incentive per year $=\mathrm{S} \$ 35.70 \times 365$ days $=\mathrm{S} \$ 13,030.50$

Thus, there will be $\mathrm{S} \$ 13,030.50$ savings per year.

From (5.14), the participant is able to recover the money invested in DR after 0.75 year.

\subsection{Cost-Benefit Analysis of Energy storage}

The electricity tariff will be different during the peak and off-peak periods. The energy storage can be charged during the off-peak period with low electricity price and discharged during the peak period while the electricity price is high. By discharging the energy storage during peak period, the smart grid operator will be able to gain higher profit compared to buying energy from the grid during the peak period. This model is developed based on this concept to explore the cost and benefit of employing the energy storage in the smart grid. The model will calculate the annual electricity cost saving achieved by the energy storage. The input parameters for the energy storage model are energy storage capacity, grid off- 
peak period electricity tariff, electricity tariff charged to consumer and minimum state of charge $S O C_{\min }$. The developed model will calculate the difference of charging cost and discharging cost according to the electricity cost in order to obtain the total annual saving. The deep discharged capacity $C_{d d c}$ for the energy storage and total annual saving $S$ is calculated as given by (5.16) and (5.17) respectively.

$$
C_{d d c}=\left(1-S O C_{\min }\right) \times C_{E S}
$$

$$
S=\sum_{i=1}^{8760}\left(P_{\text {sell }}-P_{o f f-p e a k}\right) \times C_{d d c}
$$

where $C_{E S}$ is the energy storage capacity in $\mathrm{kWh}, P_{\text {sell }}$ is the electricity tariff charged to consumer in $\$ / \mathrm{kWh}$ and $P_{\text {off-Peak }}$ is the grid off-peak period electricity tariff in $\$ / \mathrm{kWh}$.

In this case scenario, the capital cost for a $45 \mathrm{kWh}$ energy storage system is $\mathrm{S} \$ 41,735.35$. As storage requires extensive maintenance, the fixed $O \& M$ cost of $S \$ 32 / \mathrm{kW}-\mathrm{yr}$ is considered [44]. Thus, the annual O\&M cost for the $45 \mathrm{kWh}$ energy storage system is estimated at $S \$ 1,440$. The off-peak period electricity price for high tension large supplies is $\mathrm{S} \$ 0.1444 / \mathrm{kWh}$. The $S O C_{\min }$ is set as $20 \%$.

Then, the deeply discharged capacity $=\frac{100-20}{100} \times 45 \mathrm{kWh}=36 \mathrm{kWh}$.

As the grid peak price for high tension large supplies is $\mathrm{S} \$ 0.2345 / \mathrm{kWh}$, the smart grid operator need to sell at higher price in order to gain profit that can be used to pay back the energy storage investment. The potential electricity tariff charged to consumer that can be set by the smart grid operator and the simple payback period for the energy storage is given in Table 5.6. 
It can be seen that very long payback period is expected for energy storage system as the capital cost particularly the manufacturing cost and transportation cost is still significantly high. Even at $100 \%$ profit margin, i.e., consumers are charged twice the grid peak price, the payback period is 10.72 years. Energy storage such as lithium ion batteries typically can perform 1200 charging-discharging cycle. At 1 cycle per day, the energy storage can only be used for 3-4 years.

Table 5.6: Energy storage cost and benefit analysis

\begin{tabular}{|c|c|c|c|c|}
\hline $\begin{array}{c}\text { Profit } \\
\text { Margin } \\
(\%)\end{array}$ & $\begin{array}{c}\text { Off-peak } \\
\text { electricity cost to } \\
\text { smart grid } \\
\text { operator } \\
(\mathrm{S} \$ / \mathrm{kWh})\end{array}$ & $\begin{array}{c}\text { Electricity } \\
\text { tariff charged } \\
\text { to consumer } \\
(\mathrm{S} \$ / \mathrm{kWh})\end{array}$ & $\begin{array}{c}\text { Total revenue } \\
\text { per day }(\mathrm{S} \$)\end{array}$ & $\begin{array}{c}\text { Simple payback } \\
\text { period (years) }\end{array}$ \\
\hline 10 & 0.1444 & 0.2580 & 5.11 & 98.17 \\
\hline 20 & 0.1444 & 0.2815 & 6.17 & 51.4 \\
\hline 30 & 0.1444 & 0.3049 & 7.22 & 34.92 \\
\hline 40 & 0.1444 & 0.3284 & 8.28 & 26.38 \\
\hline 50 & 0.1444 & 0.3518 & 9.33 & 17.74 \\
\hline 60 & 0.1444 & 0.3753 & 10.39 & 15.26 \\
\hline 70 & 0.1444 & 0.3987 & 11.44 & 13.37 \\
\hline 80 & 0.1444 & 0.4222 & 12.50 & 11.89 \\
\hline 90 & 0.1444 & 0.4457 & 13.56 & 14.61 \\
\hline 100 & 0.1444 & 0.4691 & & 10.72 \\
\hline
\end{tabular}

However, advanced energy storage markets are generally still in a pre-commercialized stage. As such, the cost of energy storage devices is expected to decrease over the next 20 years. The following are some major benefits to deploy energy storage in a smart grid.

- Integration of renewable energy into the grid: Energy storage can be controlled to limit power fluctuations due to intermittency of PV or wind generations; 
- Frequency regulation: Energy storage can store energy in order to overcome frequency instabilities;

- Voltage control: Energy storage can help to maintain the voltage profile within a defined range, with the aim to guarantee the quality of supply. Energy storage achieves this by storing energy when the voltage is high, and delivering energy when voltage is low;

- Uninterruptible Power Supply (UPS): Energy storage can function as UPS, typical duration is 15 minutes to 1 hour.

It is can be seen that the value of implementing energy storage into the smart grid is not only for the payback of investment but also for achieving other ancillary functions within the smart grid.

\subsection{Summary}

In this section, detailed cost-benefit analyses of advanced metering infrastructure, demand side management, and EV conversion were performed. However, some of the constraints are independent of the utility, some conditions can be influenced by the utility or by the regulatory entity, and some conditions can be chosen by the utility. As such, the suggested methodology includes procedure for the selection of smart grid technologies, the selection of their characteristics, their allocations, and their respective priorities. 


\section{Chapter 6}

\section{Conclusions and Recommendations for Future Research}

\subsection{Conclusions}

One of the key issues when dealing with smart grid systems is the requirement for an adequate control and management strategy operated in decentralized manner due to the tremendous increase in dimension and complexity of the system. This thesis proposes a novel multi-microgrid hierarchical architecture design using MAS concept that will be able to achieve local and global control objectives and has the capability to handle a multiobjective and multi-constraint complex system. The optimization algorithm was developed for energy trading between different microgrids within a smart grid system to ensure power balance. The multi-microgrid energy management problem has been re-formulated as a MILP optimization with the objective to minimize the total energy cost subjected to DER generation, power balance, transmission cable power limits and transmission loss constraints. The optimization algorithm ensures that excess PV generation is fully utilized and cheaper energy sources are utilized first to ensure reduced energy cost. During islanded mode of operation, in absence of the grid supply, the proposed algorithm can optimally dispatch the microturbine and consider executing load shedding through demand response in order to meet the total load demand requirement of the multi-microgrid system. Three test case scenarios on grid-connected and islanded modes of operation have been analyzed to show the capability of the optimization algorithm to ensure power balance in the smart grid system with multiple microgrids in an economic manner while ensuring transmission cable power limits are not violated and minimum transmission cable power losses are incurred.

The research works involved to efficiently integrate intermittent DERs into the smart grid's multi-microgrid architecture with MAS concepts, includes the research and development of a hierarchical architecture design for a stable, reliable, secure and sustainable microgrid, 
research and development model-based optimization algorithm for better management of various network entities such as DERs and customer loads, and research and development on the extension of the microgrid system to establish a large interconnected and expandable smart multi-microgrid system.

The study also provides the business case model for EMS integration of smart grid in Singapore. The developed model is able to demonstrate the detailed cost-benefit justification for integration of advanced metering, demand response management, energy efficiency system, consumer participation and suitable demand side management functions in Singapore. In addition, home, building and electric vehicle load demand models are also developed for use by business case model to perform the demand side management and demand response management cost-benefit analyses.

\subsection{Recommendations}

For future works the research work can be expanded to further improve the schemes proposed in this thesis.

\section{$>$ Cost-benefit analysis of DG management}

DG management provides utilities/smart grid operators with the capability to maximize asset utilization and optimize management of the distribution network through coordinated management of DGs and demands on an interactive common platform. In the future, the design and development of an Energy Portal to compute the simple levelized cost of energy (SLCOE) of various DGs can be developed.

\section{$>$ Cost-benefit analysis of demand side management}

An efficient demand side management is required to provide attractive solutions which will (i) enable consumers to monitor and manage their energy consumption according to changes in the energy price and hence achieve peak shaving; (ii) shift their usual usage 
from peak to off-peak periods; (iii) prioritize the way they use energy; and (iv) reduce their overall energy costs. The cost-benefit analysis of demand side management for smart grid can be further developed using the same methodology of DR described earlier.

\section{$>$ Cost-benefit analysis of energy efficiency system}

Home and building energy management systems provides the basis for demand side management. Thus, further developed of home and building energy management systems in order to obtain measurements from all electrical devices/equipment at the consumer premises is required. These measured data will give the information on the amount of energy and cost that can be saved through energy efficiency system. The analysis model will evaluate feasible cost reduction that can be achieved through the implementation of various energy efficiency programs such as incorporating simple control over lights and outlets in the consumers' premises with timers, motion sensors, and dimmers. 


\section{References}

[1] Q. Jiang, M. Xue, and G. Geng, "Energy management of microgrid in gridconnected and stand-alone modes," IEEE Trans. Power System, vol. 28, no. 3, pp. 3380-3389, Aug. 2013.

[2] J. A. Pecas Lopes, C. L. Moreira, and A. G. Madureira, "Defining control strategies for microgrids islanded operation,” IEEE Trans. Power Systems, vol. 21, no. 2, pp. 916-924, May 2006.

[3] Architecture of microgrid (2009) [Online]. Available: http://bit.ly/f98iSX.

[4] X. Fang, S. Misra, G. Xue, and D. Yang, "Smart grid-The new and improved power grid: A survey," IEEE Commun. Surveys Tuts., vol. 14,no. 4, pp. 944-980, 4th Quart., 2012.

[5] J. Cheam, "Govt outlines resource, environment goals in \$1b blueprint," The Straits Times, Singapore Press Holdings, 28 Apr. 2009, pp. A1.

[6] Housing Development Board (HDB) InfoWEB, Solar capability building programme for public housing [Online]. Available: http://www.hdb.gov.sg/, Sep. 2011.

[7] J. Cheam, "Green blueprint - $80 \%$ of buildings to be eco-friendly by 2030 ," The Straits Times, Singapore Press Holdings, 28 Apr. 2009, pp. B4.

[8] HDB InfoWEB, HDB to develop Punggol as Singapore's first eco-town for the tropics [Online]. Available: http://www.hdb.gov.sg/, Jan. 2010.

[9] R. Wong, "Solar potential of HDB blocks in Singapore," Energy Studies Institute Bulletin, vol. 4, no. 3, pp. 6-7, Dec. 2011.

[10] A. Takeuchi, T. Hayashi, Y. Nozaki, and T. Shimakage, "Optimal scheduling using metaheuristics for energy networks," IEEE Trans. Smart Grid, vol. 3, no. 2, pp. 968-974, Jun. 2012.

[11] S. J. Ahn, S. R. Nam, J. H. Choi, and S. I. Moon, "Power scheduling of distributed generators for economic and stable operation of microgrid," IEEE Trans. Smart Grid, vol. 4, no. 1, pp. 398-405, Mar. 2013. 
[12] A. Parisio, E. Rikos, and L. Glielmo, "A model predictive control approach to microgrid operation optimization," IEEE Trans. Control Systems Technology, vol. 2, no. 5, pp. 1813-1827, Sep. 2014.

[13] U.S. Department of Energy, Smart Grid: Enabler of the New Energy Economy (Washington, DC: Electricity Advisroy Committee, 2008) [Online]. Available: http://www.oe.energy.gov/DocumentsandMedia/final-smart-grid-report.pdf.

[14] A. G. Tsikalakis and N. D. Hatziargyriou, "Centralized control for optimizing microgrids operation,” IEEE Trans. Energy Conversion, vol. 23, no. 1, pp. 241-248, Mar. 2008.

[15] A. Bracale, R. Angelino, G. Carpinelli, D. Lauria, M. Mangoni, and D. Proto, "Centralized control of dispersed generators providing ancillary services in distribution networks," in Proc. 44th IEEE International Universities Power Engineering Conference, 2009, pp. 1-5.

[16] T. Suehiro and T. Namerikawa, "Decentralized control of smart grid by using overlapping information," in Proc. IEEE SICE Annual Conference, 2012, pp. 125130.

[17] I. Sommerville, centralized control [Online]. Available: http://ifs.host.cs.standrews.ac.uk/Books/SE9/Web/Architecture/ArchPatterns/CentralControl.html

[18] S. D. J. McArthur, E. M. Davidson, V. M. Catterson, A. L. Dimeas, N. D. Hatziargyriou, F. Ponci, and T. Funabashi, "Multi-Agent Systems for Power Engineering Applications-Part I: Concepts, Approaches, and Technical Challenges," IEEE Trans. Power Systems, vol. 22, no. 4, pp. 1743-1752, Nov 2007

[19] L. M. Tolbert, et al., "Scalable multi-agent system for real-time electric power management," in Power Engineering Society Summer Meeting, 2001. IEEE, vol. 3, pp. 1676-1679, 2001

[20] T. Logenthiran, D. Srinivasan, A. Khambadkone, and H. Aung, "Multiagent system for real-time operation of microgrids in real-time digital simulator," IEEE Trans. Smart Grid, vol. 3, no. 2, pp. 925-933, Jun. 2012. 
[21] C. M. Colson, M. H. Nehrir, and S. A. Pourmousavi, "Towards real-time microgrid power management using computational intelligence methods," in Proc. IEEE Power and Energy Society General Meeting, 2010, pp. 1-8.

[22] C. M. Colson, M. H. Nehrir, and C. Wang, "Ant colony optimization for microgrid multi-objective power management," in Proc. IEEE Power Systems Conference and Exposition, 2009, pp. 1-7.

[23] E. Alvarez, A. C. Lopez, J. Gomez-Aleixandre, and N. D. Abajo, "On-line minimization of running costs, greenhouse gas emissions and the impact of distributed generation using microgrids on the electrical system," in Proc. IEEE PES/IAS Conference on Sustainable Alternative Energy, 2009, pp. 1-10.

[24] H. Kanchev, D. Lu, B. Francois, and V. Lazarov, "Smart monitoring of a microgrid including gas turbines and a dispatched PV-based active generator for energy management and emissions reduction," in Proc. IEEE PES Innovative Smart Grid Technologies Conference, 2010, pp. 1-8.

[25] H. Kanchev, D. Lu, F. Colas, V. Lazarov, and B. Francois, "Energy management and operational planning of a microgrid with a PV-based active generator for smart grid applications," IEEE Trans. Industrial Electronics, vol. 58, no. 10, pp. 45834592, Oct. 2011.

[26] E. J. Ng and R. A. El-Shatshat, "Multi-microgrid control systems (MMCS)," in Proc. IEEE Power and Energy Society General Meeting, 2010, pp. 1-6.

[27] W. Jiang and G. Xiaohong, "Coordinated multi-microgrids optimal control algorithm for smart distribution management system," IEEE Trans. Smart Grid, vol. 4, no. 4, pp. 2174-2181, Dec. 2013.

[28] G. E. Asimakopoulou, A. L. Dimeas, and N. D. Hatziargyriou, "Leader-follower strategies for energy management of multi-microgrids," IEEE Trans. Smart Grid, vol. 4, no. 4, pp. 1909-1916, Dec. 2013.

[29] Integer programming [Online].

Available: http://en.wikipedia.org/wiki/Integer_programming. 
[30] S. J. Chiang, K. T. Chang, and C. Y. Yen, "Residential photovoltaic energy storage system," IEEE Trans. on Industrial Electronics, vol. 45, no. 3, pp. 385-194, 1998.

[31] EMA Media Release, September 2010 [Online].

Available: http://www.ema.gov.sg/news/view/212.

[32] RFP - Smart Grid Cost-Benefit Analysis for CL\&P, July 2009 [Online].

Available: http://www.smartgridnews.com/.

[33] National Environmental Agency of Singapore, Weather Statistics [Online]. Available: http://app2.nea.gov.sg/.

[34] Energy Market Authority of Singapore, Singapore's LNG Terminal Starts Commercial Operations [Online].

Available: http://www.ema.gov.sg/news/view/606.

[35] Y. Xu, H. Li, and L. M. Tolbert, "Inverter-based microgrid control and stable islanding transition," in Proc. IEEE Energy Conversion Congress and Exposition, 2012, pp. 2374-2380.

[36] G. Shen, X. Zhu, M. Chen, and D. Xu, “A new current feedback PR control strategy for grid-connected VSI with an LCL filter," in Proc. IEEE Applied Power Electronics Conference and Exposition, 2009, pp. 1564-1569.

[37] W. Stefanutti and P. Mattavelli, "Fully digital hysteresis modulation with switching-time prediction," IEEE Trans. Industrial Applications, vol. 42, no. 3, pp. 763-769, May/Jun. 2006.

[38] K. T. Tan, P. L. So, Y. C. Chu, and M. Z. Q. Chen, "Coordinated control and energy management of distributed generation inverters in a microgrid," IEEE Trans. Power Delivery, vol. 28, no. 2, pp. 704-713, Apr. 2013.

[39] "Projected costs of generating electricity," IEA, Paris, France, 2010.

[40] SP Services, Electricity Tariffs [Online].

Available: http://www.singaporepower.com.sg.

[41] CPLEX 12 Solver Description [Online]. Available: http://www.gams.com/dd/docs/solvers/cplex.pdf.

[42] Chartwell AMR Report, 11th Edition [Online]. Available: http://www.energylibrary.com. 
[43] Energy Market Authority: Implementing demand response in the national electricity market of Singapore [Online]. Available: http://www.ema.gov.sg/dr/.

[44] National Renewable Energy Laboratory, Cost and performance data for power generation technologies [Online].

Available: www.bv.com/docs/reports-studies/nrel-cost-report.pdf. 


\section{VITA}

Ren Jiasheng was born in 1984 in P. R. China. He received the B.Eng. degree in Electrical and Electronic Engineering from Nanyang Technological University, Singapore, in 2013. $\mathrm{He}$ is pursuing his Master of Engineering (MEng.) degree at Nanyang Technological University. His research interests include energy management, mixed-integer linear programming, multi-microgrids and smart grids. He is currently working as an Engineer in the Power \& OCS Department, SBS Transit Ltd, Singapore.

List of publications.

\section{Journal Papers:}

J. S. Ren, B. Sivaneasan, K. T. Tan, and P. L. So, "Hierarchical Design Architecture for Energy Management of a Multi-Microgrid System," submitted to IEEE Power and Energy Technology Systems Journal, 2017.

\section{Conference Papers:}

J. S. Ren, B. Sivaneasan, K. T. Tan, P. L. So, and E. Gunawan, "Energy Management of a Multi-Agent Based Multi-Microgrid System," IEEE PES Asia-Pacific Power and Energy Engineering Conference(APPEEC), 2014.

\section{Book Chapter:}

K. Nandha Kumar, B. Sivaneasan, K. T. Tan, J. S. Ren, and P. L. So. Electric Vehicles as Energy Storage: V2G Capacity Estimation. In Energy Storage for Smart Grids: Planning and Operation for Renewable and Variable Energy Resources (VERs), Elsevier (Published in Oct 2014). 